\title{
Analysis of star and delta connected modular multilevel cascaded converter-based STATCOM for load unbalanced compensation
}

\author{
O.J.K. Oghorada *, Li Zhang \\ School of Electronic and Electrical Engineering, University of Leeds, United Kingdom
}

\section{A R T I C L E I N F O}

\section{Article history:}

Received 22 March 2017

Received in revised form 25 July 2017

Accepted 21 August 2017

Available online 3 September 2017

\section{Keywords:}

Multilevel converter

STATCOM

Unbalance load

Star

Delta

\begin{abstract}
A B S T R A C T
This paper compares the operating capabilities of STATCOMs based on Modular Multilevel Cascaded Converters (MMCC) using star and delta connections, with special attention to unbalanced load compensation. Zero sequence voltage for star connection, and zero sequence current for delta, need to be applied to overcome the phase cluster DC-voltage unbalance. Expressions are derived for both zero sequence elements as functions of the degree of load unbalance defined as the ratio of negative to positive sequence load current. They show that the zero sequence voltage in star connection reaches a very high level as the degree of load unbalance increases, making the MMCC DC-link voltage too high for correct functioning. However the delta connected MMCC can cope with the high level of load current unbalance. Experimental results are presented to validate this analysis.
\end{abstract}

(c) 2017 Elsevier Ltd. All rights reserved.

\section{Introduction}

The Voltage Source Converter (VSC) based-Static Synchronous Compensator (STATCOM) is now an established and highly effective device for voltage control and reactive power compensation in power networks [1-3]. Compared to its predecessors, such as the thyristor-controlled SVC, the STATCOM has the advantages of fast response, high flexibility and low harmonic injection to the grid. With continuing changes in power systems, notably electricity market deregulation, increasing interconnection and wider use of the less predictable renewable energy sources, the need for development of STATCOMs and other FACTS devices, such as Synchronous Series Compensator (SSSC), Unified Power Flow Controller (UPFC), becomes ever more pressing. Important aspects are the selection of installation locations, the selection and optimal parameter tuning for STATCOM and other FACTS devices, to deliver high performance control of voltage and power and damp out disturbances during transient states [4-6]. On the other hand, worldwide interest has been drawn to Modular Multi-level Cascaded Converters (MMCC) as possible next-generation inverters for

Abbreviations: STATCOM, Static Synchronous Compensator; MMCC, Modular Multilevel Cascaded Converter; SSBC, Single Star Bridge Converter; SDBC, Single Delta Bridge Converter; VSC, Voltage Source Converter; NPC, Neutral Point Clamped; 2L-HB, Two-level H-Bridge; 3L-FCC, Three-level Flying Capacitor Converter; PCC, Point of Common Coupling.

* Corresponding author.

E-mail address: el11oo@leeds.ac.uk (O.J.K. Oghorada).
STATCOMs and many other applications [7-9] in medium and high voltage $(11 \mathrm{kV}$ up to $200 \mathrm{kV})$ power systems. The commonly accepted MMCC uses single-phase H-bridge VSCs as fundamental building blocks which are serially stacked to form a phase limb. The three-phase limbs of an MMCC may be in either star or delta connection, hence being classified as Single-Star Bridge Converter MMCC (SSBC-MMCC) and Single-Delta Bridge Converter MMCC [10-12].

With proper control, STATCOMs can be equally capable for unbalanced load mitigation. Typical causes of unbalance are large single-phase loads such as traction drives, arc furnaces, adjustable speed drives and switch-mode power supplies. Renewable energy sources frequently appear as unbalanced generators, rather than loads.

Such loads cause unbalanced line voltage drops, and hence unbalanced network voltages at the point of common coupling. All loads connected to the affected points would be supplied with distorted unbalanced voltages, causing undesired effects of equipment malfunction, resonance and even damage, and low power factor and increased line losses and harmonics in power systems. When using a STATCOM to compensate the unbalanced load current, it should identify and then actively supply the required negative-sequence component of the load current, thus rebalancing the currents at the point of common coupling (PCC). The STATCOM converters used for this application are typically two-level H-bridge types with step-up transformers, [13,14] while classical multilevel converters, such as Neutral Point Clamped 


\section{Nomenclature}

List of Symbols and Abbreviations

$\boldsymbol{v}_{\boldsymbol{o}}, \boldsymbol{i}_{\boldsymbol{o}} \quad$ zero sequence voltage and current

$\boldsymbol{k}_{\text {ir }} \quad$ degree of Load unbalance, $\boldsymbol{I}_{\boldsymbol{n}} / \boldsymbol{I}_{\boldsymbol{p}}$

$\boldsymbol{I}_{\boldsymbol{p}}, \boldsymbol{I}_{\boldsymbol{n}} \quad$ positive and negative sequence currents

$\varphi_{i p}, \varphi_{i n}$ positive and negative sequence current phase angles

$\boldsymbol{V}_{\boldsymbol{p}} \quad$ Supply side phase voltage

$\varphi_{v p} \quad$ Voltage phase angle

$I_{\boldsymbol{d} \_ \text {ref }}$ reference converter positive sequence active current

$\boldsymbol{V}_{\boldsymbol{D C} \_ \text {avg }}$ average value of three phase sub-module capacitor voltages

$\boldsymbol{V}_{\boldsymbol{D C} \boldsymbol{i}} \quad$ average value of phase sub-module capacitor voltages, where $i=a, b, c$ or $a b, b c, c a$ $\boldsymbol{n}_{\boldsymbol{m} \boldsymbol{p}} \quad$ number of sub-modules per phase

$\boldsymbol{K}_{p_{-} d \boldsymbol{d}}, \boldsymbol{K}_{\boldsymbol{i}_{-} \boldsymbol{d c}}$ Active Current proportional and integral controller gains

$\boldsymbol{K}_{\boldsymbol{p}_{-} \boldsymbol{i}}, \boldsymbol{K}_{\boldsymbol{i}_{-} \boldsymbol{i}}$ cluster voltage balancing proportional and integral controller gains per phases

$\boldsymbol{V}_{\boldsymbol{S}} \quad$ Maximum Supply side voltage

$\boldsymbol{V}_{\boldsymbol{D C}} \quad$ nominal sub-module capacitor voltage

$\boldsymbol{i}_{\boldsymbol{s}} \quad$ supply side current

$v_{\boldsymbol{c} i} \quad$ converter cluster reference voltages where $i=a, b, c$ or $a b, b c, c a$

$\boldsymbol{i}_{\boldsymbol{c} i} \quad$ converter cluster currents where $i=a, b, c$ or $a b, b c, c a$
(NPC) types, have also been applied [15]. Recently both SSBCMMCC and SDBC-MMCC-based STATCOMs have been investigated for use in unbalanced current compensation [16-21], though these treatments are all for unbalance caused by PV power generation. Benefits of MMCC-based STATCOMs over conventional topologies are modularity and hence scalability, using their modular nature to extend to any voltage level required without step-up transformers [19-21], and good output voltage waveform quality at low switching frequencies. The switching and clamping devices in an MMCC can be rated at modular level, enabling it to use devices rated at lower powers and withstanding lower voltage stresses. However when an MMCC-based STATCOM operates under unbalanced loading it faces the challenge of DC-link voltage imbalance. This is caused by non-zero active power flowing between the converter phase limbs. Where the STATCOMs of two-level or classical multilevel converters can have three phase limbs sharing a common dc-link, for MMCCs the stacked H-bridge modules have their respective DC-capacitors isolated from each other, so no active power exchange between phases is possible. Consequently DClink voltages may drift away from their desired levels, resulting in STATCOM malfunction and excessive device stress or damage. Various methods for addressing this problem have been investigated [16,22,23]; one approach for SSBC MMCC is to inject a sinusoidal zero-sequence voltage to balance the power between phase clusters[23,24]. This, however, restricts the STATCOM's capability in load unbalance compensation since the total DC-link capacitor voltage available in each phase cluster is reduced. Other approaches being proposed for extending the compensation level are in the context of using MMCCs for grid-connected PV systems[25-28] where the idea is to inject a non-sinusoidal zero sequence voltage with harmonic contents across each cluster. In the case of the SDBC MMCC, the proposed approach has been to inject a zero sequence current [15,20]. In [29], the authors gave a detailed analysis on the limitations of various methods for both the SSBC and SDBC MMCCs, assuming applications requiring active power injection into the grid system and not yet treating reactive power and unbalanced load compensation. Authors in [23] illustrated the relationship between the cluster voltage references and the degree of current imbalance but not specifying the operating range of the SSBC inverter for unbalanced load compensation.

This paper investigates the MMCC STATCOM for both reactive power and unbalanced current compensations. A new result from the work is the detailed derivation of explicit expressions for the zero sequence voltage as a function of the degree of load current imbalance for the SSBC converter, and for zero sequence current as a function of load current imbalance for the SDBC. These equations will enable the quantifications of the converter ratings required or compensating a given degree of load unbalance. The analysis will give the operation range limits of both types of
MMCC-STATCOMs when operating under unbalanced loading and while performing voltage and power factor regulation.

The paper is structured as follows. Section 2 presents the circuit configurations of the SSBC and SDBC MMCC when the building blocks are either two-level H-bridge or three-level full-bridge flying capacitor converters (3L-FCC). Section 3 presents the problems of unbalanced voltage caused by non-zero active power for both types of STATCOM when compensating an unbalanced load. Subsequently their individual control schemes are discussed in Section 4. In Section 5, the operating ranges of both SSBC and SDBC are analysed. To validate this analysis, experimental results are discussed in Section 6.

\section{Circuit configurations of MMCC-based STATCOMS}

An MMCC-based STATCOM may be in either star (SSBC) or delta connections (SDBC) as illustrated in Fig. 1(a) and (b) respectively. For SSBC the neutral points of the supply and converter sides are not connected together. The basic cells in the phase clusters can be either two level H-bridge (2L-HB) or three level flying capacitor cells (3L-FCC). Both topologies, outlined below, have been used for STATCOM applications [10,11].

\section{Analysis of inter cluster DC-voltage imbalance}

For both SSBC and SDBC MMCC-based STATCOMs, irrespective of their cell topology, when they are used for unbalanced load compensation, the problems of DC voltage imbalance between the three phase clusters (inter-cluster) occurs. This is due to the compensating negative sequence current generating a non-zero active power inside the converter clusters thus resulting in sub-module DC capacitor voltages to be unbalance. This imbalance can be analysed for both converter configurations as follows.

\subsection{The SSBC MMCC-based STATCOM}

The phase voltages at the point of common coupling (PCC) having magnitude $\boldsymbol{V}_{\boldsymbol{P}}$ and phase angle $\boldsymbol{\varphi}_{\boldsymbol{V} \boldsymbol{P}}$ can be written as:

$v_{a}=V_{p} e^{j \varphi_{V P}}, v_{b}=V_{p} e^{j\left(\varphi_{V P}-\frac{2 \pi}{3}\right)}, v_{c}=V_{p} e^{j\left(\varphi_{V P}+\frac{2 \pi}{3}\right)}$

For unbalanced load compensation the STATCOM reference phase currents comprise a positive and negative sequence components, $\boldsymbol{I}_{\boldsymbol{P}}$ and $\boldsymbol{I}_{\boldsymbol{n}}$, given as:

$$
\begin{aligned}
& i_{r a}^{*}=I_{p} e^{j \varphi_{i p}}+I_{n} e^{j \varphi_{i n}} \\
& i_{r b}^{*}=I_{p} e^{j\left(\varphi_{i p}-\frac{2 \pi}{3}\right)}+I_{n} e^{j\left(\varphi_{i n}+\frac{2 \pi}{3}\right)} \\
& i_{r c}^{*}=I_{p} e^{j\left(\varphi_{i p}+\frac{2 \pi}{3}\right)}+I_{n} e^{j\left(\varphi_{i n}-\frac{2 \pi}{3}\right)}
\end{aligned}
$$




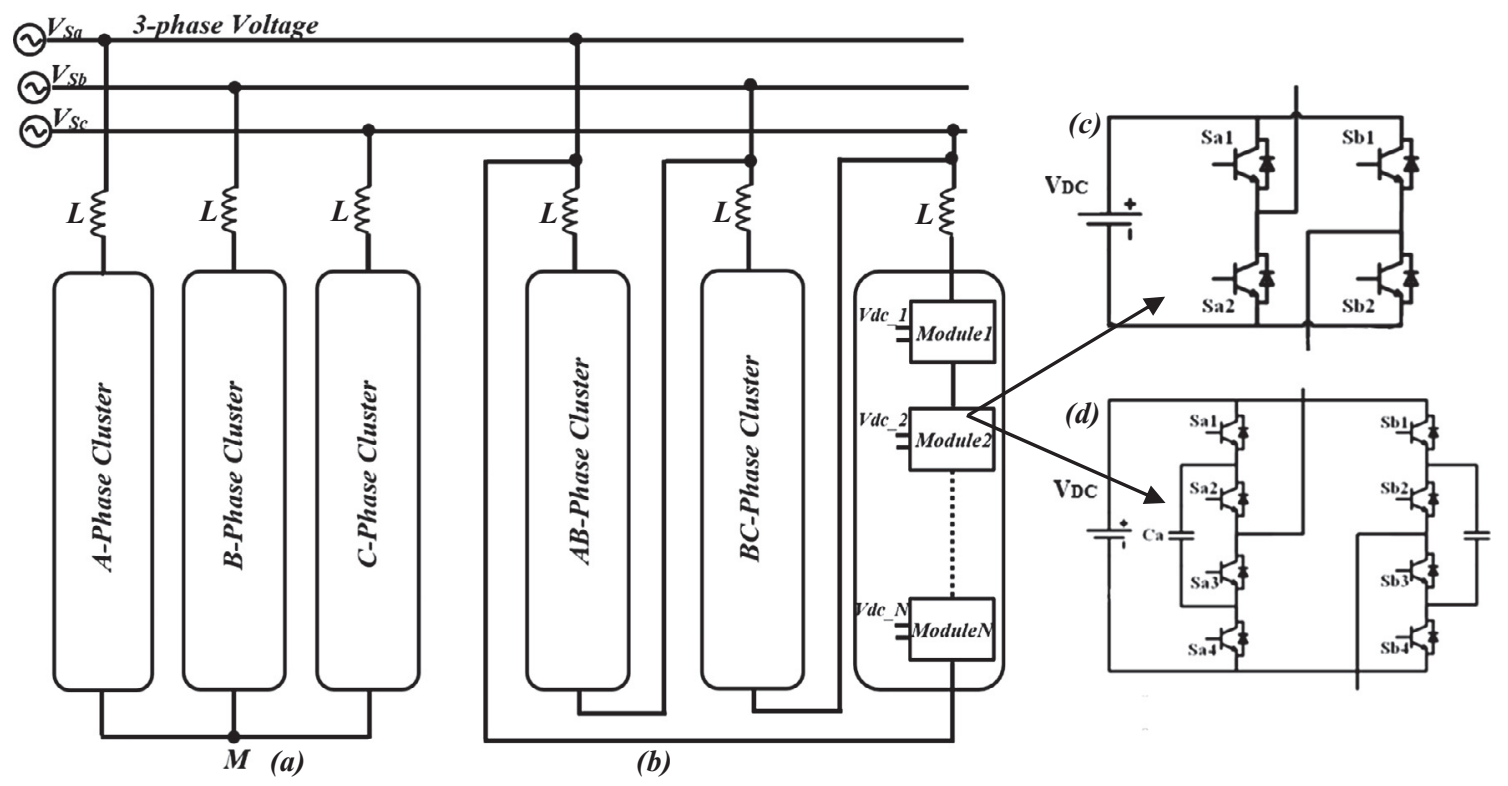

Fig. 1. Two MMCC STATCOM systems: (a) SSBC, (b) SDBC and (c) 2L-FB, (d) 3L-FCC.

where $\varphi_{i p}, \varphi_{i n}$ are respectively the phase angles of the positive and negative sequence currents taking their respective PCC phase voltages as references. Thus the total active power per phase cluster is expressed as:

$$
\begin{aligned}
& P_{a}=R\left[\left(V_{p} e^{j \varphi_{V P}}\right)\left(I_{p} e^{-j \varphi_{i p}}+I_{n} e^{-j \varphi_{i n}}\right)\right]=\underbrace{V_{p} I_{p} \cos \left(\varphi_{V P}-\varphi_{i p}\right)}_{\text {First term }} \\
& +\underbrace{V_{p} I_{n} \cos \left(\varphi_{V P}-\varphi_{\text {in }}\right)}_{\text {Second term }} \\
& P_{b}=R\left[\left(V_{p} e^{j\left(\varphi_{V P}-\frac{2 \pi}{3}\right)}\right)\left(I_{p} e^{-j\left(\varphi_{i p}-\frac{2 \pi}{3}\right)}+I_{n} e^{-j\left(\varphi_{i n}+\frac{2 \pi}{3}\right)}\right)\right] \\
& =\underbrace{V_{p} I_{p} \cos \left(\varphi_{V P}-\varphi_{i p}\right)}_{\text {First term }}+\underbrace{V_{p} I_{n} \cos \left(\varphi_{V P}-\varphi_{\text {in }}+\frac{2 \pi}{3}\right)}_{\text {Second term }} \\
& P_{c}=R\left[\left(V_{p} e^{j\left(\varphi_{\text {VP }}+\frac{2 \pi}{3}\right)}\right)\left(I_{p} e^{-j\left(\varphi_{i p}+\frac{2 \pi}{3}\right)}+I_{n} e^{-j\left(\varphi_{i n}-\frac{2 \pi}{3}\right)}\right)\right] \\
& =\underbrace{V_{p} I_{p} \cos \left(\varphi_{V P}-\varphi_{i p}\right)}_{\text {First term }}+\underbrace{V_{p} I_{n} \cos \left(\varphi_{V P}-\varphi_{\text {in }}-\frac{2 \pi}{3}\right)}_{\text {Second term }}
\end{aligned}
$$

The first term in each of the above three expressions is the active power due to positive-sequence current for compensating converter losses. This power is taken from the grid and is equal for the three phases and is regulated through the active power control as will be discussed in Section 4.1. The second terms are crossproducts of positive and negative sequence voltage and current, they are non-zero and not equal. The isolated DC-links of the stacked modules in each phase cluster do not allow active power exchange between phases, resulting in inter cluster DC-link voltage imbalance.

An effective method involves adding a common zero-sequence voltage to the inverter star point $\mathbf{M}$. such that the active power generate by the zero sequence cancels out the effect of the nonzero active power terms in each phases without interfering with the three-phase voltage and current at the network side.

\subsection{The SDBC-based STATCOM}

In this case the-per phase cluster powers are based on voltage across each phase limb and current flowing through it. Note that the line-to-line voltage at PCC $v_{a b}$ corresponds to converter delta phase limb voltages $v_{p \Delta n}(\mathrm{n}=\mathrm{a}, \mathrm{b}, \mathrm{c})$ and are expressed as:

$$
\begin{aligned}
& v_{p \Delta a}=v_{a b}=\left(v_{a}-v_{b}\right)=\sqrt{3} V_{p} e^{j\left(\varphi_{V P}+\frac{\pi}{6}\right)} \\
& v_{p \Delta b}=v_{b c}=\left(v_{b}-v_{c}\right)=\sqrt{3} V_{p} e^{j\left(\varphi_{V P}-\frac{\pi}{2}\right)} \\
& v_{p \Delta c}=v_{c a}=\left(v_{c}-v_{a}\right)=\sqrt{3} V_{p} e^{j\left(\varphi_{V P}+\frac{5 \pi}{6}\right)} \\
& i_{r a b}^{*}=\frac{1}{\sqrt{3}}\left(I_{p} e^{j\left(\varphi_{i p}+\frac{\pi}{6}\right)}+I_{n} e^{j\left(\varphi_{i n}-\frac{\pi}{6}\right)}\right) \\
& i_{r b c}^{*}=\frac{1}{\sqrt{3}}\left(I_{p} e^{j\left(\varphi_{i p}-\frac{\pi}{2}\right)}+I_{n} e^{j\left(\varphi_{i n}+\frac{\pi}{2}\right)}\right) \\
& i_{r c a}^{*}=\frac{1}{\sqrt{3}}\left(I_{p} e^{j\left(\varphi_{i p}+\frac{5 \pi}{6}\right)}+I_{n} e^{j\left(\varphi_{i n}-\frac{5 \pi}{6}\right)}\right)
\end{aligned}
$$

So the active power per phase is given as:

$$
\begin{aligned}
P_{a b} & =R\left[\left(\sqrt{3} V_{p} e^{j\left(\varphi_{V P}+\frac{\pi}{6}\right)}\right)\left(\frac{1}{\sqrt{3}}\left(I_{p} e^{-j\left(\varphi_{i p}+\frac{\pi}{6}\right)}+I_{n} e^{-j\left(\varphi_{i n}-\frac{\pi}{6}\right)}\right)\right)\right] \\
& =\underbrace{V_{p} I_{p} \cos \left(\varphi_{V P}-\varphi_{i p}\right)}_{\text {First term }}+\underbrace{V_{p} I_{n} \cos \left(\varphi_{V P}-\varphi_{\text {in }}+\frac{\pi}{3}\right)}_{\text {Second term }} \\
P_{b c} & =R\left[\left(\sqrt{3} V_{p} e^{j\left(\varphi_{V P}-\frac{\pi}{2}\right)}\right)\left(\frac{1}{\sqrt{3}}\left(I_{p} e^{-j\left(\varphi_{i p}-\frac{\pi}{2}\right)}+I_{n} e^{-j\left(\varphi_{i n}+\frac{\pi}{2}\right)}\right)\right)\right] \\
& =\underbrace{V_{p} I_{p} \cos \left(\varphi_{V P}-\varphi_{i p}\right)}_{\text {First term }}+\underbrace{V_{p} I_{n} \cos \left(\varphi_{V P}-\varphi_{\text {in }}+\pi\right)}_{\text {Second term }} \\
P_{c a} & =R\left[( \sqrt { 3 } V _ { p } e ^ { j ( \varphi _ { V P } + \frac { 5 \pi } { 6 } ) } ) \left(\frac{1}{\sqrt{3}}\right.\right. \\
& =\underbrace{V_{p} I_{p} \cos \left(\varphi_{V P}-\varphi_{i p}\right)}_{\text {First term }}+\underbrace{\left.\left.\left.I_{p} e^{-j\left(\varphi_{i p}+\frac{5 \pi}{6}\right)}+I_{n} e^{-j\left(\varphi_{\text {in }}-\frac{5 \pi}{6}\right)}\right)\right)\right]}_{\text {Second term }}
\end{aligned}
$$

Similar to the SSBC case the non-zero and non-equal active powers expressed by the second terms of the above power equations would cause cluster DC-voltages imbalance and the method to overcome this is to inject a zero sequence current $\boldsymbol{i}_{\boldsymbol{o}}$ through the converter phase clusters to ensure the active power due to negative current across each cluster is nullified.

\section{Inter cluster voltage balancing control}

As mentioned earlier the voltage balance control for SSBC configuration relies on deriving zero-sequence voltage $\boldsymbol{v}_{\boldsymbol{o}}$ and that for 
SDBC needs zero-sequence current $\boldsymbol{i}_{\boldsymbol{o}}$. Both can be obtained based on evaluating the required phase powers $\boldsymbol{P}_{\boldsymbol{a}}^{*}, \boldsymbol{P}_{\boldsymbol{b}}^{*}, \boldsymbol{P}_{\boldsymbol{c}}^{*}$ (cluster active powers) which can ensure balanced phase-cluster voltages using voltage feedback loops. These active power evaluations are discussed below.

\subsection{Active power/current evaluation}

As shown in (3) and (6) respectively, there are two active power elements flowing through each phase limb. The first element, due to compensating converter losses, depends on the active current, $\boldsymbol{I}_{\boldsymbol{d} \_ \text {ref, }}$ required for maintaining the average value of the three phase-limb DC-bus voltages to the nominal level. This current can be evaluated using the well-known DC-bus voltage feedback control scheme as illustrated in Fig. 2(a). Obtaining the average value, $\boldsymbol{V}_{\mathbf{D C} \_\boldsymbol{a v g}}$, of the three phase-limb DC-link voltages requires calculating per phase limb average DC voltage. This can be done by averaging the measured individual module voltages within the corresponding phase chain, so the DC-link average voltages for each phase are given respectively as:

$$
\begin{aligned}
V_{D C_{\_} a} & =\frac{1}{n_{m p}} \sum_{i=1}^{n_{m p}} V_{D C_{\_} i a}, V_{D C_{\_} b}=\frac{1}{n_{m p}} \sum_{i=1}^{n_{m p}} V_{D C_{\_} i b}, V_{D C_{\_} c} \\
& =\frac{1}{n_{m p}} \sum_{i=1}^{n_{m p}} V_{D C_{\_} i c}
\end{aligned}
$$

where $\boldsymbol{n}_{\boldsymbol{m} \boldsymbol{p}}$ denotes the number of sub-modules per phase and $\boldsymbol{V}_{\boldsymbol{D C} \_ \text {avg }}$ can be evaluated as:

$V_{D C_{\_} a v g}=\frac{V_{D C_{\_} a}+V_{D C_{\_} b}+V_{D C_{\_} c}}{3}$

For the second power element which is the negative sequence active power relies on implementing a cluster voltage balancing control scheme since it is this power flowing in and out of each converter phase limb causing the imbalance of the phase limb DC-link voltages. As shown in Fig. 2(b) this cluster voltage balancing control consist of three PI regulators respectively for each phase limb. The reference voltage for the three voltage controllers

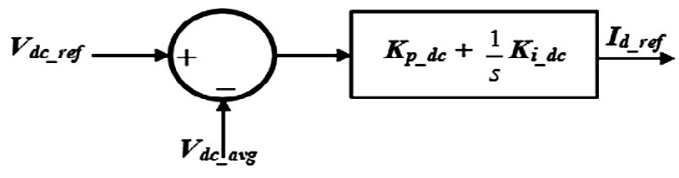

(a)

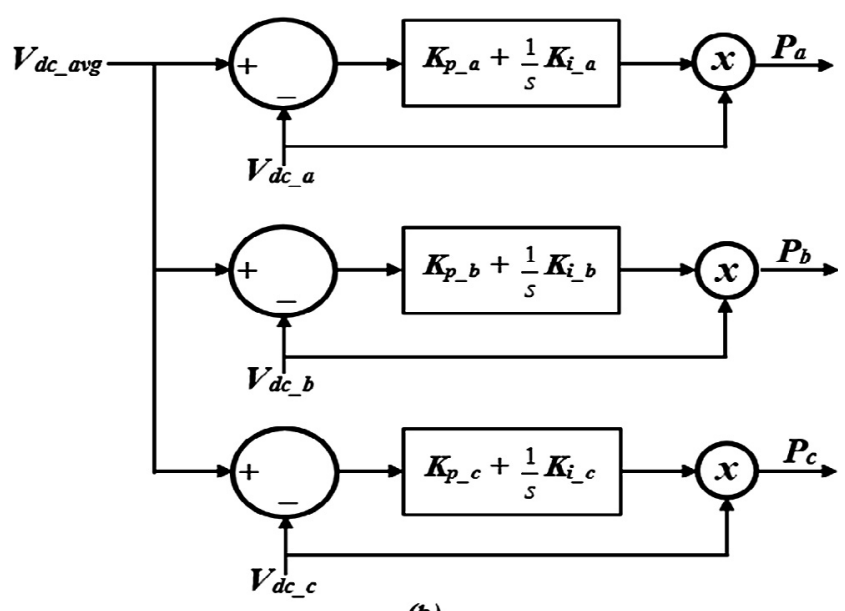

(b)

Fig. 2. Active power/current compensation controllers: (a) Active current compensation controller and (b) cluster voltage balancing controller. is the same average voltage $\boldsymbol{V}_{\boldsymbol{D C} \text { avg }}$ evaluated in (8) and feedback voltages are the respective phase limb average voltages (i.e. $\boldsymbol{V}_{\boldsymbol{D C} \_\boldsymbol{a}}$, $\boldsymbol{V}_{\boldsymbol{D C} \boldsymbol{C}_{-} \boldsymbol{b}}$ and $\boldsymbol{V}_{\boldsymbol{D} \boldsymbol{C}_{-} \boldsymbol{c}}$ ) as derived by (7). The output of each regulator generates the reference active power for the corresponding phase of the STATCOM converter and will be used to determine the common zero sequence components to be injected in both configurations.

\subsection{SSBC: zero-sequence voltage $v_{o}$ estimation}

Estimation of $\boldsymbol{v}_{\boldsymbol{o}}$ follows the principle that the sum of active power caused by the injected zero sequence voltage and that of existing active power expressed in (3) should balance the reference powers from cluster voltage control loop in Fig. 2(b). Thus the equations for power across each phase including the term due to $\boldsymbol{v}_{\boldsymbol{o}}$ are written as:

$$
\begin{aligned}
P_{a}= & R\left[\left(V_{p} e^{j \varphi_{V P}}+V_{o} e^{j \varphi_{o}}\right)\left(I_{p} e^{-j \varphi_{i p}}+I_{n} e^{-j \varphi_{i n}}\right)\right] \\
= & V_{p} I_{p} \cos \left(\varphi_{V P}-\varphi_{i p}\right)+V_{p} I_{n} \cos \left(\varphi_{V P}-\varphi_{i n}\right) \\
& +V_{o} I_{p} \cos \left(\varphi_{o}-\varphi_{i p}\right)+V_{o} I_{n} \cos \left(\varphi_{o}-\varphi_{i n}\right) \\
P_{b}= & R\left[\left(V_{p} e^{j\left(\varphi_{V P}-\frac{2 \pi}{3}\right)}++V_{o} e^{j \varphi_{o}}\right)\left(I_{p} e^{-j\left(\varphi_{i p}-\frac{2 \pi}{3}\right)}+I_{n} e^{-j\left(\varphi_{i n}+\frac{2 \pi}{3}\right)}\right)\right] \\
= & V_{p} I_{p} \cos \left(\varphi_{V P}-\varphi_{i p}\right)+V_{p} I_{n} \cos \left(\varphi_{V P}-\varphi_{i n}+\frac{2 \pi}{3}\right) \\
& +V_{o} I_{p} \cos \left(\varphi_{o}-\varphi_{i p}+\frac{2 \pi}{3}\right)+V_{o} I_{n} \cos \left(\varphi_{o}-\varphi_{i n}-\frac{2 \pi}{3}\right) \\
P_{c}= & R\left[\left(V_{p} e^{j\left(\varphi_{V P}+\frac{2 \pi}{3}\right)}++V_{o} e^{j \varphi_{o}}\right)\left(I_{p} e^{-j\left(\varphi_{i p}+\frac{2 \pi}{3}\right)}+I_{n} e^{-j\left(\varphi_{i n}-\frac{2 \pi}{3}\right)}\right)\right] \\
= & V_{p} I_{p} \cos \left(\varphi_{V P}-\varphi_{i p}\right)+V_{p} I_{n} \cos \left(\varphi_{V P}-\varphi_{i n}+\frac{2 \pi}{3}\right) \\
& +V_{o} I_{p} \cos \left(\varphi_{o}-\varphi_{i p}+\frac{2 \pi}{3}\right)+V_{o} I_{n} \cos \left(\varphi_{o}-\varphi_{i n}-\frac{2 \pi}{3}\right)
\end{aligned}
$$

Any two of the above three power equations can be used to determine the amplitude and phase angle of $\boldsymbol{v}_{\boldsymbol{o}}$. Assuming the first two are used they can be written as:

$$
\begin{aligned}
& V_{o} I_{p} \cos \left(\varphi_{o}-\varphi_{i p}\right)+V_{o} I_{n} \cos \left(\varphi_{o}-\varphi_{i n}\right) \\
& \quad=P_{a}-\left(V_{p} I_{p} \cos \left(\varphi_{V P}-\varphi_{i p}\right)+V_{p} I_{n} \cos \left(\varphi_{V P}-\varphi_{i n}\right)\right) \\
& V_{o} I_{p} \cos \left(\varphi_{o}-\varphi_{i p}+\frac{2 \pi}{3}\right)+V_{o} I_{n} \cos \left(\varphi_{o}-\varphi_{i n}-\frac{2 \pi}{3}\right) \\
& \quad=P_{b}-\left(V_{p} I_{p} \cos \left(\varphi_{V P}-\varphi_{i p}\right)+V_{p} I_{n} \cos \left(\varphi_{V P}-\varphi_{i n}+\frac{2 \pi}{3}\right)\right)
\end{aligned}
$$

and their more compact forms are given as:

$$
\begin{aligned}
& X_{a 1} V_{o} \cos \varphi_{o}+X_{a 2} V_{o} \sin \varphi_{o}=P_{a}-X_{a 3} \\
& X_{b 1} V_{o} \cos \varphi_{o}+X_{b 2} V_{o} \sin \varphi_{o}=P_{b}-X_{b 3}
\end{aligned}
$$

Simplifying (11) yields:

$$
\begin{aligned}
V_{o} & =\frac{\left(P_{a}-X_{a 3}\right)}{X_{a 1} \cos \varphi_{o}+X_{a 2} \sin \varphi_{o}} \\
\varphi_{o} & =\arctan \left[\frac{\left(P_{a}-X_{a 3}\right) X_{b 1}-\left(P_{b}-X_{b 3}\right) X_{a 1}}{\left(P_{b}-X_{b 3}\right) X_{a 2}-\left(P_{a}-X_{a 3}\right) X_{b 2}}\right]
\end{aligned}
$$

where $\left(X_{a 1}=I_{p} \cos \varphi_{i p}+I_{n} \cos \varphi_{i n}, X_{a 2}=I_{p} \sin \varphi_{i p}+I_{n} \sin \varphi_{i n}\right.$,

$$
\begin{aligned}
X_{a 3} & =V_{p} I_{p} \cos \left(\varphi_{V P}-\varphi_{i p}\right)+V_{p} I_{n} \cos \left(\varphi_{V P}-\varphi_{i n}\right) \\
X_{b 1} & =I_{p} \cos \left(\varphi_{i p}-\frac{2 \pi}{3}\right)+I_{n} \cos \left(\varphi_{i n}+\frac{2 \pi}{3}\right), X_{b 2} \\
& =I_{p} \sin \left(\varphi_{i p}-\frac{2 \pi}{3}\right)+I_{n} \sin \left(\varphi_{i n}+\frac{2 \pi}{3}\right),
\end{aligned}
$$

$X_{a 3}=V_{p} I_{p} \cos \left(\varphi_{V P}-\varphi_{i p}\right)+V_{p} I_{n} \cos \left(\varphi_{V P}-\varphi_{i n}+\frac{2 \pi}{3}\right)$ 
and its time domain instantaneous voltage is expressed as:

$v_{o}=V_{o} \sin \left(w t-\varphi_{o}\right)$

where $\theta=\omega t$ is the synchronous rotating angle created by the phase locked loop (PLL).

\subsection{SDBC: zero-sequence current $i_{o}$ estimation}

In this case the cluster active powers evaluated from voltage feedback control (Fig. 2(b)) are $\boldsymbol{P}_{\boldsymbol{a b}}, \boldsymbol{P}_{\boldsymbol{b c}}$ and $\boldsymbol{P}_{\boldsymbol{c a}}$, and are equal to the sum of active power caused by the injected zero sequence current $\boldsymbol{i}_{\boldsymbol{o}}$ and that of existing active power expressed in (6), thus we have,

$$
\begin{aligned}
P_{a b}= & R\left[\left(\sqrt{3} V_{p} e^{j\left(\varphi_{V P}+\frac{\pi}{6}\right)}\right)\left(\frac{1}{\sqrt{3}}\left(I_{p} e^{-j\left(\varphi_{i p}+\frac{\pi}{6}\right)}+I_{n} e^{-j\left(\varphi_{i n}-\frac{\pi}{6}\right)}\right)+I_{o} e^{-j \varphi_{o}}\right)\right] \\
= & V_{p} I_{p} \cos \left(\varphi_{V P}-\varphi_{i p}\right)+V_{p} I_{n} \cos \left(\varphi_{V P}-\varphi_{i n}+\frac{\pi}{3}\right) \\
& +\sqrt{3} V_{p} I_{o} \cos \left(\varphi_{V P}-\varphi_{o}+\frac{\pi}{6}\right) \\
P_{b c}= & R\left[\left(\sqrt{3} V_{p} e^{j\left(\varphi_{V P}-\frac{\pi}{2}\right)}\right)\left(\frac{1}{\sqrt{3}}\left(I_{p} e^{-j\left(\varphi_{i p}-\frac{\pi}{2}\right)}+I_{n} e^{-j\left(\varphi_{i n}+\frac{\pi}{2}\right)}\right)+I_{o} e^{-j \varphi_{o}}\right)\right] \\
= & V_{p} I_{p} \cos \left(\varphi_{V P}-\varphi_{i p}\right)+V_{p} I_{n} \cos \left(\varphi_{V P}-\varphi_{i n}+\pi\right) \\
& +\sqrt{3} V_{p} I_{o} \cos \left(\varphi_{V P}-\varphi_{o}-\frac{\pi}{2}\right) \\
P_{c a}= & R\left[\left(\sqrt{3} V_{p} e^{j\left(\varphi_{V P}+\frac{5 \pi}{6}\right)}\right)\left(\frac{1}{\sqrt{3}}\left(I_{p} e^{-j\left(\varphi_{i p}+\frac{5 \pi}{6}\right)}+I_{n} e^{-j\left(\varphi_{i n}-\frac{5 \pi}{6}\right)}\right)+I_{o} e^{-j \varphi_{o}}\right)\right] \\
= & V_{p} I_{p} \cos \left(\varphi_{V P}-\varphi_{i p}\right)+V_{p} I_{n} \cos \left(\varphi_{V P}-\varphi_{i n}+\frac{5 \pi}{3}\right) \\
& +\sqrt{3} V_{p} I_{o} \cos \left(\varphi_{V P}-\varphi_{o}+\frac{5 \pi}{6}\right)
\end{aligned}
$$

Any two power equations above can be used to determine the amplitude and phase angle of $\boldsymbol{i}_{\boldsymbol{o}}$, and the first two are chosen they can be written as:

$$
\begin{aligned}
& \sqrt{3} V_{p} I_{o} \cos \left(\varphi_{V P}-\varphi_{o}+\frac{\pi}{6}\right)=P_{a b}-\left(V_{p} I_{p} \cos \left(\varphi_{V P}-\varphi_{i p}\right)\right. \\
& \left.\quad+V_{p} I_{n} \cos \left(\varphi_{V P}-\varphi_{i n}+\frac{\pi}{3}\right)\right) \\
& \sqrt{3} V_{p} I_{o} \cos \left(\varphi_{V P}-\varphi_{o}-\frac{\pi}{2}\right)=P_{b c}-\left(V_{p} I_{p} \cos \left(\varphi_{V P}-\varphi_{i p}\right)\right. \\
& \left.+V_{p} I_{n} \cos \left(\varphi_{V P}-\varphi_{i n}-\pi\right)\right)
\end{aligned}
$$

and their more compact forms are given as:

$$
\begin{aligned}
& X_{a b 1} I_{o} \cos \varphi_{o}+X_{a b 2} I_{o} \sin \varphi_{o}=P_{a b}-X_{a b 3} \\
& X_{b c 1} I_{o} \cos \varphi_{o}+X_{b c 2} I_{o} \sin \varphi_{o}=P_{b c}-X_{b c 3}
\end{aligned}
$$

where $X_{a b 1}=\sqrt{3} V_{p} \cos \left(\varphi_{V P}+\frac{\pi}{6}\right), X_{a b 2}=\sqrt{3} V_{p} \sin \left(\varphi_{V P}+\frac{\pi}{6}\right)$,

$X_{a b 3}=V_{p} I_{p} \cos \left(\varphi_{V P}-\varphi_{i p}\right)+V_{p} I_{n} \cos \left(\varphi_{V P}-\varphi_{i n}+\frac{\pi}{3}\right)$

$X_{b c 1}=\sqrt{3} V_{p} \cos \left(\varphi_{V P}-\frac{\pi}{2}\right), X_{b c 2}=\sqrt{3} V_{p} \sin \left(\varphi_{V P}-\frac{\pi}{2}\right)$,

$X_{a 3}=V_{p} I_{p} \cos \left(\varphi_{V P}-\varphi_{i p}\right)+V_{p} I_{n} \cos \left(\varphi_{V P}-\varphi_{\text {in }}-\pi\right)$

From (17) the zero sequence current amplitude and phase angle can be derived as:

$I_{o}=\frac{\left(P_{a b}-X_{a b 3}\right)}{X_{a b 1} \cos \varphi_{o}+X_{a b 2} \sin \varphi_{o}}$

$\varphi_{o}=\arctan \left[\frac{\left(P_{a b}-X_{a b 3}\right) X_{b c 1}-\left(P_{b c}-X_{b c 3}\right) X_{a b 1}}{\left(P_{b c}-X_{b c 3}\right) X_{a b 2}-\left(P_{a b}-X_{a b 3}\right) X_{b c 2}}\right]$

and its time domain instantaneous formular is expressed as

$i_{o}=I_{o} \sin \left(w t-\varphi_{o}\right)$
Fig. 3 shows the flowchart of the control algorithm for both SSBC and SDBC STATCOMs for performing reactive power and unbalanced load compensations. Firstly the negative sequence and positive sequence reactive currents are extracted from the measured load current, leaving only the positive sequence active currents which will be supplied by the source at PCC. Meanwhile the required active current due for the overall sub-module dc capacitor voltage balancing is computed. Both these current elements are combined to form the STATCOM reference value for its current control. The next step involves evaluating the magnitude and angle of zero sequence components ( $v_{0}$ for SSBC and $i_{o}$ for SDBC). These use the currents evaluated from the first step, PCC voltages and the inter-cluster active powers and apply Eqs. (12) and (13) or (18) and (20). The calculated zero sequence components are then combined with the reference converter voltages obtained from the current control loop, forming the reference voltage signals required by the PWM scheme for the converter switching control.

\section{Analysis and comparison of operation ranges}

There is an adverse effect caused by injecting the common zero sequence voltage and current respectively to SSBC and SDBC converters for balancing their inter phase cluster sub-module DC-link voltages. That is the capability of the converters in compensating the grid unbalanced load may be reduced due to the total DC-link capacitor voltage/current available in each cluster being limited. This can be analysed by investigating the variations of $\boldsymbol{v}_{\boldsymbol{o}}$ and $\boldsymbol{i}_{\boldsymbol{o}}$ as functions of the degree of load unbalance which is defined by the modulus of ratio of negative and positive sequence currents give as:

$K_{i r}=\frac{I_{n}}{I_{p}}$

\subsection{SSBC: zero sequence voltage VS degree of unbalance}

The amplitude and phase angle of the sinusoidal zero sequence voltage $\boldsymbol{v}_{\boldsymbol{o}}$ are expressed respectively by Eqs. (12) and (13), substituting their corresponding terms in (14) and expanding sine term using trigonometric identity gives-

$v_{o}=\frac{\left(P_{a}-X_{a 3}\right)}{X_{a 1} \cos \varphi_{o}+X_{a 2} \sin \varphi_{o}}\left(\sin \omega t \cos \varphi_{o}+\cos \omega t \sin \varphi_{o}\right)$

Dividing the RHS term numerator and denominator by $\cos \varphi_{o}$ gives;

$v_{o}=\frac{\left(P_{a}-X_{a 3}\right)}{X_{a 1} \cos \varphi_{o}+X_{a 2} \tan \varphi_{o}}\left(\sin \omega t+\cos \omega \operatorname{ttan} \varphi_{o}\right)$

According to $\varphi_{o}$ given by (13),

$\tan \varphi_{o}=\left[\frac{\left(P_{a}-X_{a 3}\right) X_{b 1}-\left(P_{b}-X_{b 3}\right) X_{a 1}}{\left(P_{b}-X_{b 3}\right) X_{a 2}-\left(P_{a}-X_{a 3}\right) X_{b 2}}\right]$

Substituting $\tan \varphi_{o}$ in (23) by the above expression and rearrange we have;

$\begin{aligned} v_{o} & =\left[\frac{\left[\left(P_{b}-X_{b 3}\right) X_{a 2}-\left(P_{a}-X_{a 3}\right) X_{b 2}\right] \sin \omega t+\left[\left(P_{a}-X_{a 3}\right) X_{b 1}-\left(P_{b}-X_{b 3}\right) X_{a 1}\right] \cos \omega t}{X_{a 2} X_{b 1}-X_{a 1} X_{b 2}}\right] \\ & =\bar{D}\end{aligned}$

Simplifying (25) to show explicitly the variation of $\boldsymbol{v}_{\boldsymbol{o}}$ with respect to $\boldsymbol{I}_{\boldsymbol{p}}$ and $\boldsymbol{I}_{\boldsymbol{n}}$, we process its numerator $(\boldsymbol{N})$ and denominator (D) separately, and combine the results, the derivation process is given in Appendix A. The derived expression for $\boldsymbol{v}_{\boldsymbol{o}}$ as a function of $\boldsymbol{I}_{\boldsymbol{P}}$ and $\boldsymbol{I}_{\boldsymbol{n}}$ is given as: 


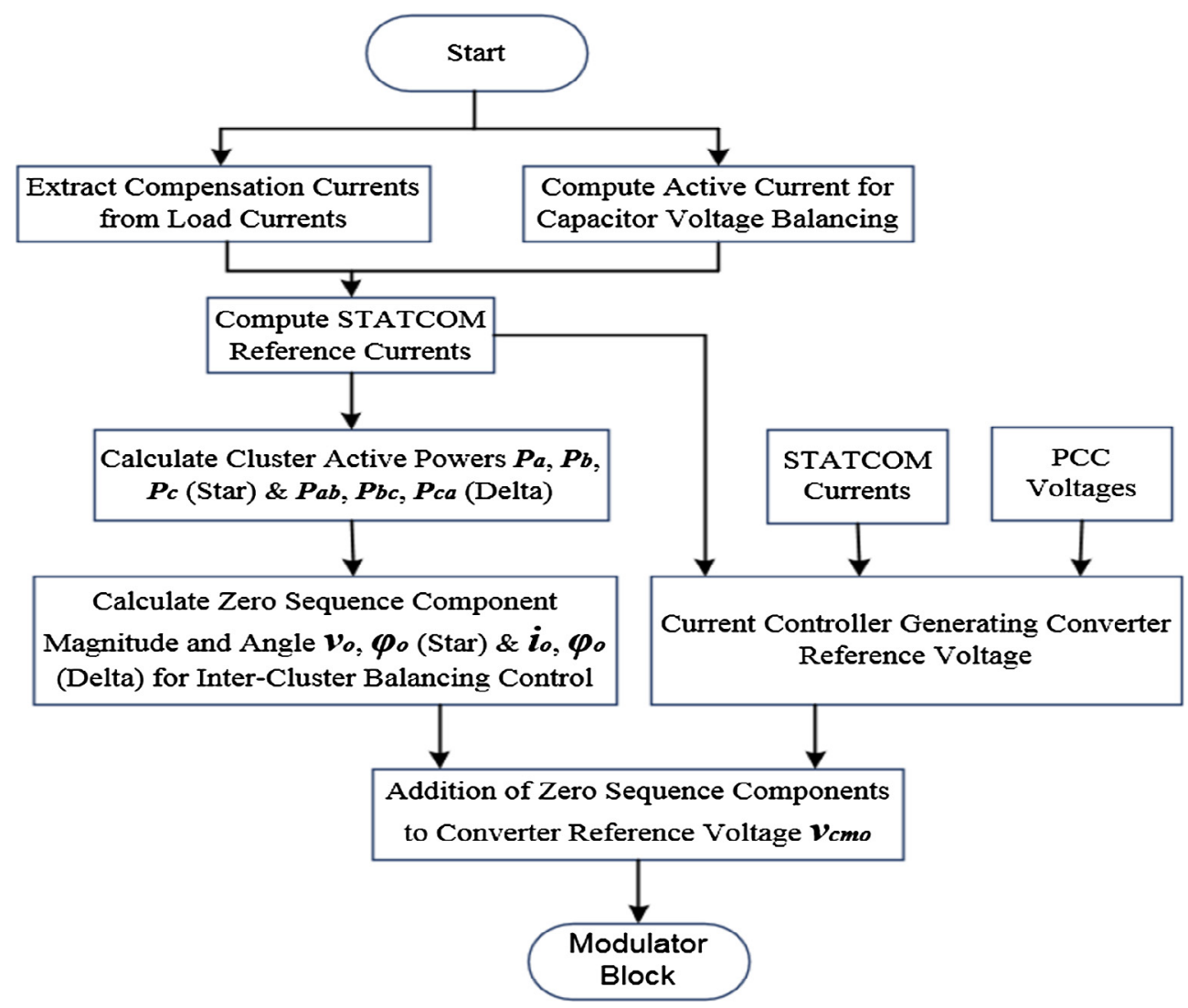

Fig. 3. Flowchart of Single cell MMCC for unbalanced load compensation.

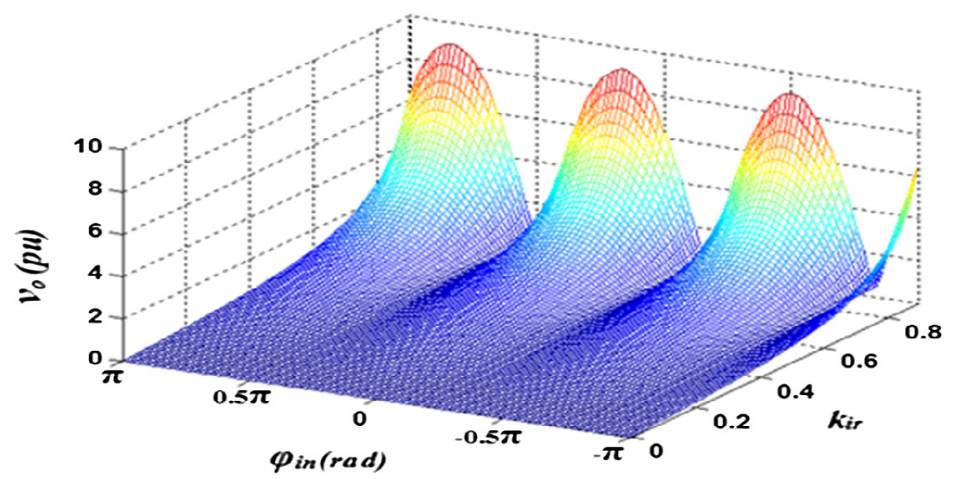

(a)
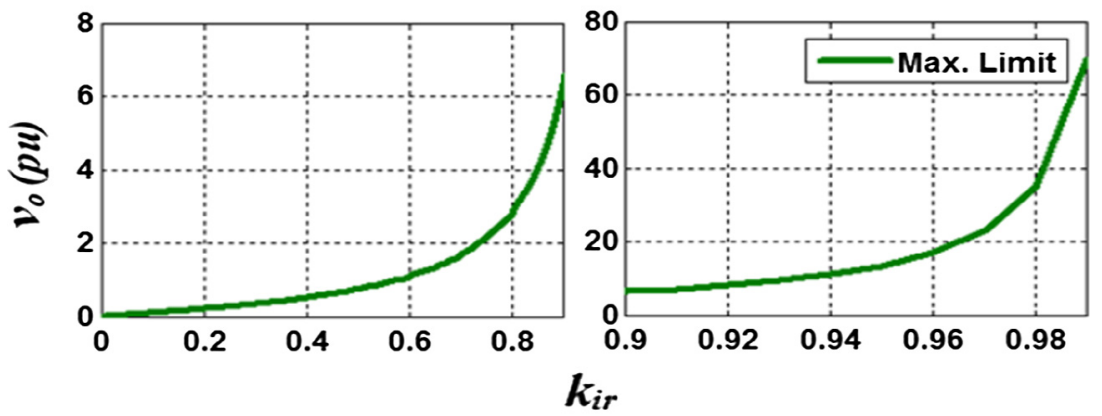

(b)

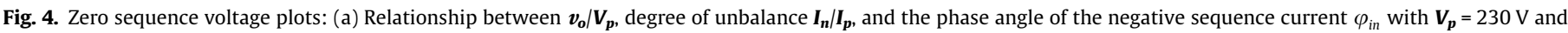
(b) Zero sequence voltage $\boldsymbol{v}_{\boldsymbol{o}}$, versus degree of unbalance $\boldsymbol{K}_{\boldsymbol{i r}}$ at $\varphi_{i n}=\pi / 6 \operatorname{rad}(\operatorname{Max}$.Limit). 


$$
\begin{aligned}
v_{o}= & \frac{2}{\sqrt{3} I_{p}^{2}\left(1-K_{i r}^{2}\right)}\left(I_{p}\left(A_{a 1} \cos \left(\omega t+\varphi_{i p}-\frac{2 \pi}{3}\right)-A_{b 1} \cos \left(\omega t+\varphi_{i p}\right)\right)\right. \\
& \left.+I_{n}\left(A_{a 1} \cos \left(\omega t+\varphi_{i n}+\frac{2 \pi}{3}\right)-A_{b 1} \cos \left(\omega t+\varphi_{i n}\right)\right)\right)
\end{aligned}
$$

where $\boldsymbol{A}_{\boldsymbol{a} \mathbf{1}}$ and $\boldsymbol{A}_{\boldsymbol{b} \boldsymbol{1}}$ are the power terms as expressed in Appendix A.

As seen from (26), $\boldsymbol{v}_{\boldsymbol{o}}$ is inversely proportional to the difference of the degree of unbalance $\boldsymbol{K}_{\boldsymbol{i r}}$ squared subtracted from 1 and directly proportional to the real components of the positive and negative sequence reference currents. This means that the magnitude of $\boldsymbol{v}_{\boldsymbol{o}}$ increases with $\boldsymbol{K}_{\boldsymbol{i r}}$ increment. In the rare case when $I_{n} \approx I_{p}, K_{i r} \approx 100 \%, v_{o} \rightarrow \infty$. The operating range of a star connected STATCOM is limited by the voltage capability of each phase cluster. When compensating a highly unbalanced load, $\boldsymbol{v}_{\boldsymbol{o}}$ is added to each converter phase voltage to ensure the inter cluster voltages being balanced. However, addition of $\boldsymbol{v}_{\boldsymbol{o}}$ leads to the converter phase voltage exceeding its rated level, therefore resulting in the SSBC operating in over-modulation mode or even becoming uncontrollable.

The relationship between the ratio of $\boldsymbol{v}_{\boldsymbol{o}}$ to phase voltage $\left(\boldsymbol{v}_{\boldsymbol{o}}\right)$ $\boldsymbol{V}_{\boldsymbol{p}}$ ), degree of unbalance $\boldsymbol{K}_{\boldsymbol{i r}}$, and the phase angle of the negative sequence current $\varphi_{\text {in }}$ is shown in Fig. 4(a). It can be observed that the magnitude of the cluster DC-link voltage must be rated higher than $\boldsymbol{V}_{\boldsymbol{p}}$ under unbalanced current compensation because $\boldsymbol{v}_{\boldsymbol{o}}$ increases beyond $\boldsymbol{V}_{\boldsymbol{p}}$ as $\boldsymbol{K}_{\boldsymbol{i r}}$ increases. The zero sequence voltage is mainly determined by $\boldsymbol{K}_{\boldsymbol{i r}}$ but independent of the magnitude of the compensated reference currents.

The maximum value of $\boldsymbol{v}_{\boldsymbol{o}}$ is generated at specific phases $\varphi_{\text {in }}=-\pi / 2 \mathrm{rad}, \pi / 6 \mathrm{rad}$ and $2 \pi / 3 \mathrm{rad}$ while minima occur at $\varphi_{\text {in }}=\pi / 2 \mathrm{rad},-\pi / 6 \mathrm{rad}$ and $-2 \pi / 3 \mathrm{rad}$. Fig. 4 (b) shows that at $\varphi_{\text {in }}=\pi / 6 \operatorname{rad}($ Max.Limit), the zero sequence voltage increases to about 9 p.u at $\boldsymbol{K}_{\boldsymbol{i r}}=0.9$, beyond this value, a steep increase of $\boldsymbol{v}_{\boldsymbol{o}}$ occurs and is illustrated in Fig. 4(b).

For a purely reactive current compensated along with unbalance current, the phase angle of the positive sequence current $\varphi_{i p}=\pi / 2$ rad and power loss is also assumed negligible $\left(P_{a}=P_{b}=P_{c}=0\right)$. With the mentioned assumption, the zero sequence voltage is simplified and given as:

$$
\begin{aligned}
v_{o}= & \frac{2 V_{p} K_{i r}}{\sqrt{3}\left(1-K_{i r}^{2}\right)}\left(\left(\frac{\sqrt{3}}{2} K_{i r} \cos \varphi_{i n}-0.5\right) \sin \left(\omega t+\varphi_{i n}\right)\right. \\
& \left.+\left(\frac{\sqrt{3}+1}{2} K_{i r} \cos \varphi_{\text {in }}-0.5 \sin \varphi_{i n}\right) \cos \left(\omega t+\varphi_{\text {in }}\right)\right)
\end{aligned}
$$

This equation establishes the dependency of $\boldsymbol{v}_{\boldsymbol{o}}$ on the degree of load unbalance without taking into consideration the magnitude of the compensated positive and negative sequence currents.

\subsection{SDBC: zero sequence current VS degree of unbalance}

The relationship of $\boldsymbol{i}_{\boldsymbol{o}}$ with degree of unbalance compensated for SDBC-based STATCOM can also be derived. Substituting (18) into (20) yields,

$$
i_{o}=\frac{\left(P_{a b}-X_{a b 3}\right)}{X_{a b 1} \cos \varphi_{o}+X_{a b 2} \sin \varphi_{o}}\left(\sin \omega t \cos \varphi_{o}+\cos \omega t \sin \varphi_{o}\right)
$$

Dividing throughout by $\cos \varphi_{o}$ gives:

$$
i_{o}=\frac{\left(P_{a b}-X_{a b 3}\right)}{X_{a b 1} \cos \varphi_{o}+X_{a b 2} \tan \varphi_{o}}\left(\sin \omega t+\cos \omega \tan \varphi_{o}\right)
$$

$$
\text { Substitution of } \tan \varphi_{o} \text { from (19) into (29) gives }
$$

$i_{o}=\left[\frac{\left[\left(P_{b c}-X_{b c 3}\right) X_{a b 2}-\left(P_{a b}-X_{a b 3}\right) X_{b c 2}\right] \sin \omega t+\left[\left(P_{a b}-X_{a b 3}\right) X_{b c 1}-\left(P_{b c}-X_{b c 3}\right) X_{a b 1}\right] \cos \omega t}{X_{a b 2} X_{b c 1}-X_{a b 1} X_{b c 2}}\right]=\frac{N}{D}$

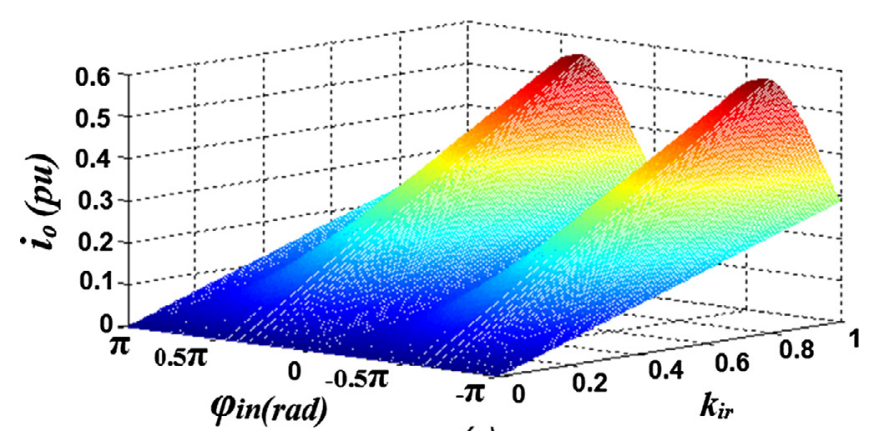

(a)

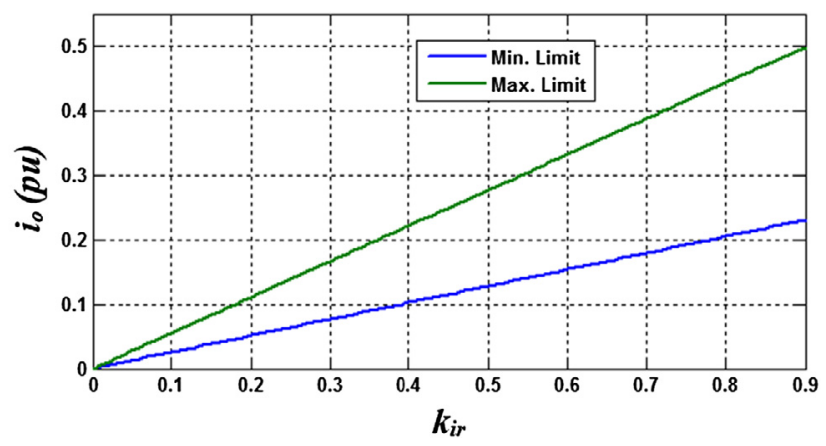

(b)

Fig. 5. Zero sequence current plots: (a) Relationship between the zero sequence current $\boldsymbol{i}_{\boldsymbol{o}}$, degree of unbalance $\boldsymbol{I}_{\boldsymbol{n}} / \boldsymbol{I}_{\boldsymbol{p}}$, and the phase angle of the negative sequence current $\varphi_{\text {in }}$ at $\boldsymbol{I}_{\boldsymbol{n}}$ and $\boldsymbol{I}_{\boldsymbol{p}}$ maximum equals $1 \mathrm{~A}$ and (b) Relationship between the zero sequence current $\boldsymbol{i}_{\boldsymbol{o}}$, and degree of unbalance $\boldsymbol{I}_{\boldsymbol{n}} / \boldsymbol{I}_{\boldsymbol{p}}$, at $\varphi_{\text {in }}=$ $-\pi / 12 \operatorname{rad}($ Min.Limit) and $5 \pi / 12 \operatorname{rad}($ Max.Limit).

The solution of the instantaneous zero sequence current is:

$$
\begin{aligned}
i_{0}= & \frac{2}{3} I_{P}\left[\left(\frac{P_{a b}}{V_{P} I_{P}}-\cos \varphi_{i p}-\frac{1}{2} K_{i r} \cos \varphi_{\text {in }}-\frac{\sqrt{3}}{2} K_{i r} \sin \varphi_{\text {in }}\right)\right. \\
& \left.\cos \left(\omega t-\frac{\pi}{2}\right)-\left(\frac{P_{b c}}{V_{P} I_{P}}-\cos \varphi_{i p}+K_{i r} \cos \varphi_{i n}\right) \cos \left(\omega t+\frac{\pi}{6}\right)\right]
\end{aligned}
$$

The simplification of (29), (30) are given in Appendix B, (31) shows that $\boldsymbol{i}_{\boldsymbol{o}}$ depends on the $\boldsymbol{K}_{i r}, \boldsymbol{I}_{\boldsymbol{p}}$ and power ratios $\boldsymbol{P}_{\boldsymbol{a b}} / \boldsymbol{I}_{\boldsymbol{p}} \boldsymbol{V}_{\boldsymbol{p}}$ and $\boldsymbol{P}_{\boldsymbol{b c}} / \boldsymbol{I}_{\boldsymbol{p}} \boldsymbol{V}_{\boldsymbol{p}}$ respectively. Eq. (31) shows that the magnitude of $\boldsymbol{i}_{\boldsymbol{o}}$ flowing in the delta-configured three-phase limbs is solely dependent on the values of the compensated current $\boldsymbol{I}_{\boldsymbol{p}}$ and $\boldsymbol{K}_{\boldsymbol{i}}$. The equation shows that, for any degree of load unbalance $\boldsymbol{i}_{\boldsymbol{o}}$ can be found for any degree of unbalance. The operating range of a delta-connected STATCOM is still limited by the degree of load unbalance to be compensated. This limitation is determined by the maximum current flowing in each converter cluster since it is a summation of $\boldsymbol{i}_{\boldsymbol{o}}$ and the cluster compensated currents.

The relationship between the ratio of $\boldsymbol{i}_{\boldsymbol{o}}$ to the phase cluster rated current $\left(\boldsymbol{i}_{\boldsymbol{o}} / \boldsymbol{I}\right)$, degree of unbalance $\boldsymbol{K}_{\boldsymbol{i}}$, and the phase angle of negative sequence current $\varphi_{i n}$ is shown in Fig. 5(a). It can be observed that the current rating of the SDBC MMCC must be rated higher than its balanced rating under unbalanced compensation currents because $\boldsymbol{i}_{\boldsymbol{o}}$ increases as $\boldsymbol{K}_{\boldsymbol{i r}}$ increases. For this analysis the converter line current is rated at $2 \mathrm{~A}$.

For a purely reactive current compensated along with unbalance current, the phase positive sequence current $\varphi_{i p}=\pi / 2 \mathrm{rad}$ and power loss is also assumed negligible $\left(P_{a b}=P_{b c}=P_{c a}=0\right)$. With the mentioned assumption, the zero sequence current is simplified and given as: 


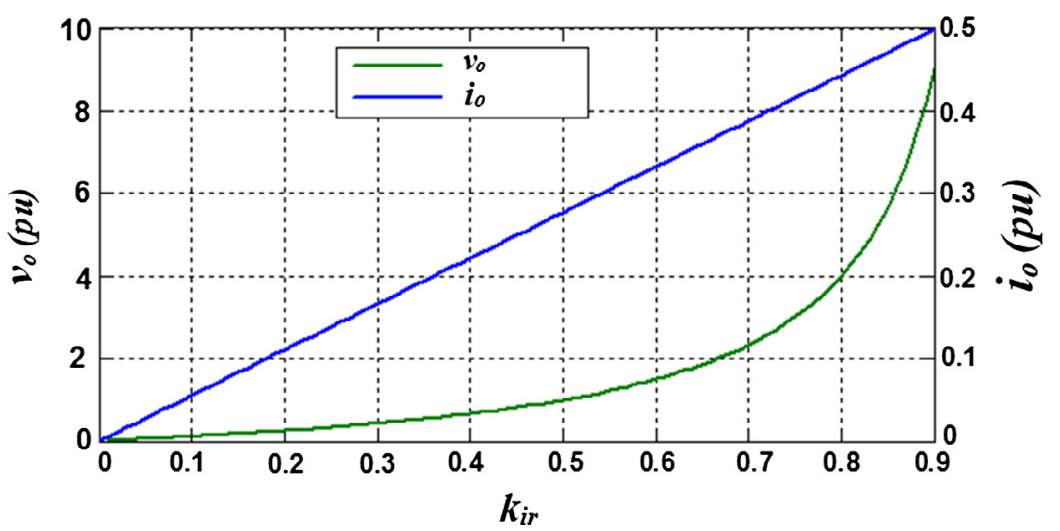

Fig. 6. Comparison between Zero sequence current and voltage for the same $\boldsymbol{K}_{\boldsymbol{i r}}=\boldsymbol{I}_{\boldsymbol{n}} / \boldsymbol{I}_{\boldsymbol{p}}$ condition at their maximum limits.

$i_{o}=-\frac{I_{n}}{\sqrt{3}} \cos \left(\omega t-\varphi_{\text {in }}\right)$

Eq. (32) establishes the dependency of the current circulating around the delta converter solely on the negative sequence current $\boldsymbol{I}_{\boldsymbol{n}}$.

Another factor that influences the magnitude of $\boldsymbol{i}_{\boldsymbol{o}}$ is $\varphi_{\text {in }}$ which defines the relationship between the negative sequence active and reactive currents. The maximum value of the zero sequence current is generated at specific angles of $\varphi_{i n}=5 \pi / 12 \mathrm{rad}$ and $-7 \pi / 12 \mathrm{rad}$ while minimum values at $\varphi_{\text {in }}=-\pi / 12 \mathrm{rad}$ and $11 \pi / 12 \mathrm{rad}$ respectively. Fig. 5(b) shows that at $\varphi_{\text {in }}=-\pi / 12 \mathrm{rad}$ (Min.Limit) and $5 \pi / 12 \operatorname{rad}($ Max.Limit), the zero sequence current rises linearly during $\boldsymbol{K}_{\boldsymbol{i r}}$ intervals of 0 to 1 .

Fig. 6 contrasts the increases of $\boldsymbol{v}_{\boldsymbol{o}}$ and $\boldsymbol{i}_{\boldsymbol{o}}$ as $\boldsymbol{K}_{\boldsymbol{i r}}$ raises from 0 to 0.9 . Note that the vertical axes on the right and left hand sides represents the magnitudes of $\boldsymbol{i}_{\boldsymbol{o}}$ and $\boldsymbol{v}_{\boldsymbol{o}}$ respectively. At the level of unbalance when $\boldsymbol{K}_{\boldsymbol{i r}}=0.9$, one can see that $\boldsymbol{i}_{\boldsymbol{o}}$ is only $0.5 \mathrm{pu}$, hence $50 \%$ of the phase nominal value, however $\boldsymbol{v}_{\mathrm{o}}$ is $9 \mathrm{pu}, 9$ times of the nominal voltage value!. From this plot, it is clear that the required magnitude of zero sequence current for balancing the inter-cluster capacitor voltage of the SDBC is far lower than the zero sequence voltage required for SSBC.

\section{Experimental results}

Experimental validations of the above analysis have been performed on a scale-down MMCC STATCOM built in the laboratory. The experimental prototype built in the laboratory is shown in Fig. 7. The prototype uses three phase MMCC with each phase cluster consisting of two series connected three level flying capacitor converter modules. The detailed system parameters of the experimental set up are given in Table 1 . The choice of filter inductor is

Table 1

Experimental circuit parameters.

\begin{tabular}{lll}
\hline Configuration & SSBC & SDBC \\
\hline Max. phase voltage $\boldsymbol{V}_{\boldsymbol{S}}$ & $60 \mathrm{~V}$ & \\
Line frequency $\boldsymbol{f}$ & $50 \mathrm{~Hz}$ & \\
Number of modules per phase cluster & 2 & \\
Nominal module capacitor voltage $\boldsymbol{V}_{\boldsymbol{D C}}$ & $50 \mathrm{~V}$ & $70 \mathrm{~V}$ \\
Nominal flying capacitor voltage $\boldsymbol{V}_{\boldsymbol{f} \boldsymbol{c}}$ & $25 \mathrm{~V}$ & $35 \mathrm{~V}$ \\
AC inductor $\boldsymbol{L}$ & $10 \mathrm{mH}$ & \\
Module Capacitor & $1120 \mu \mathrm{F}$ & \\
Flying Capacitor & $560 \mu \mathrm{F}$ & \\
Carrier frequency $\boldsymbol{f}_{\boldsymbol{c}}$ & $750 \mathrm{~Hz}$ & \\
Equivalent switching frequency & $6000 \mathrm{~Hz}$ & \\
Rated Power $\boldsymbol{S}$ & $1.05 \mathrm{KVA}$ & \\
\end{tabular}

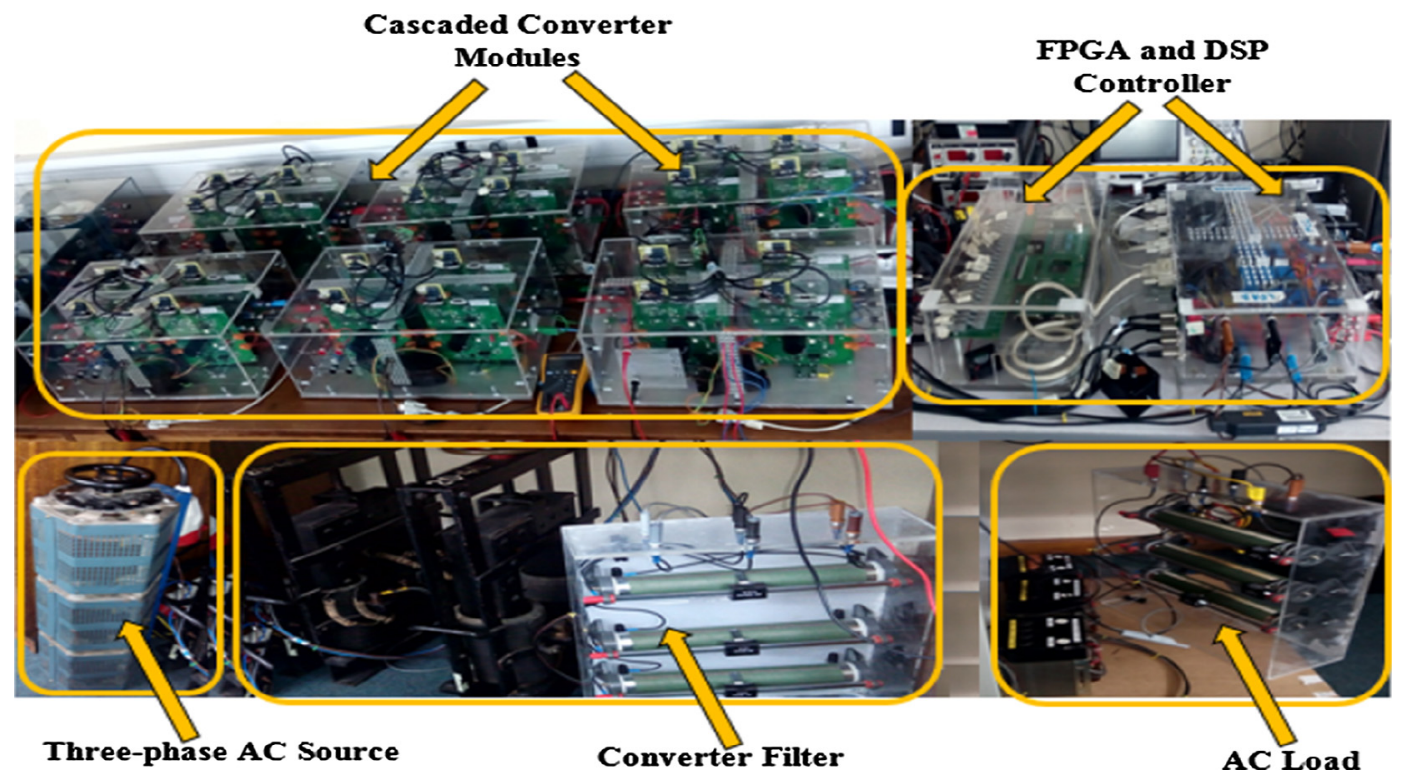

Fig. 7. Photograph of Laboratory set-up. 
according to switching harmonic spectra due to converter PWM modulation technique. Also, the sub-module capacitors were selected to ensure that their voltage ripples should not exceed $\pm 10 \%$ of its nominal voltage rating. The inter-cluster balancing proportional and integral control gains across each phase are $K_{p \_a}=K_{p \_b}=K_{p \_c}=0.5$ and $K_{i_{-} a}=K_{i_{-} b}=K_{i_{-} c}=10$.

The converter is controlled by a digital signal processor (DSPTMS320C6713) combined with a Field Programmable Gate Array (FPGA-ActelProAsic III) connected on the DSP's external memory interface. The DSP calculates the converter voltage reference signals whilst the FPGA generates the PWM gating signals.

The degree of unbalance $\boldsymbol{K}_{\boldsymbol{i r}}$ was set up to 0.7. Figs. 8 and 9 show the experimental results for star and delta configurations respectively. The order of display is as follows: (a) shows $\boldsymbol{K}_{\boldsymbol{i r}}$ variation; (b) and (c) graphs display the supply PCC end voltage and current; (d) and (e) graphs show converter cluster voltages, and the converter cluster currents, $\boldsymbol{i}_{\boldsymbol{C a b c}}$ (star) and $\boldsymbol{i}_{\boldsymbol{C a b}, \boldsymbol{b c}, \boldsymbol{c a}}$ (delta). The sub-module DClink capacitor voltages, $\boldsymbol{V}_{\boldsymbol{d} \boldsymbol{d} \_\boldsymbol{a b c}}(\mathrm{star})$ and $\boldsymbol{V}_{\boldsymbol{d c} \_\boldsymbol{a b}, \boldsymbol{b} \boldsymbol{b}, \boldsymbol{c a} \boldsymbol{a}}$ (delta), are shown in (f) and finally the zero sequence voltage or current denoted as $\boldsymbol{v}_{\boldsymbol{o}}$ (star), $\boldsymbol{i}_{\boldsymbol{o}}$ (delta) respectively is displayed in ( $\mathrm{g}$ ).

For both configurations $(0<\mathrm{t}<0.1 \mathrm{~s})$, the STATCOM performs only reactive power compensation. From $t=0.1 \mathrm{~s}$, the STATCOM controller compensates load unbalance, by increasing $K_{i r}$ in steps of $0.21,0.105,0.075$ and 0.05 up to 0.65 in Fig. 8, and in steps of 0.175 up to 0.7 in Fig. 9.
Fig. 8 shows the SSBC-based STATCOM can adequately compensating for $K_{i r}$ up to $0.6(0.1<\mathrm{t}<0.5 \mathrm{~s})$. It is observed that from $K_{i r}=0.21$, the converter starts supplying unbalanced load current (Fig. 8(e)) to compensate load unbalance, its terminal voltage becomes unbalanced (Fig. 8(d)), and $v_{0}$ starts increasing (Fig. 8 (g)). In this case the DC-link voltages are maintained at their nominal ratings $\left(50 \mathrm{~V}\right.$ ) as seen in Fig. 8 (f). When $K_{i r}$ increases to $42 \%$ $(0.2<\mathrm{t}<0.3 \mathrm{~s})$, converter terminal phase voltage becomes more unbalanced, hence pushing higher unbalanced current to rebalanced the current at PCC (Fig. 8(c)), the magnitude of $v_{0}$ reaches $30 \mathrm{~V}$ which is $50 \%$ of the converter phase nominal voltage, causing the maximum phase voltage value rising from nominal $60 \mathrm{~V}$ to $90 \mathrm{~V}$. Further increasing the load unbalance level from $K_{i r}=42 \%$ up to $60 \%$, ( $\mathrm{t}<0.5 \mathrm{~s})$, the converter can still re-balance the current at PCC, even with higher maximum phase voltages due to the required zero sequence voltage $v_{0}$ reaches $80 \%$ of the nominal phase voltage level. This is because the DC-link voltages are still held to their nominal levels. However the stable compensation operation cannot be maintained when $K_{i r}>60 \%$. Taking $K_{i r}=65 \%$ $(0.5<\mathrm{t}<0.6 \mathrm{~s})$ as an example for this case, it can be seen that the reference voltage for phase $\boldsymbol{c}$ (highlighted as red) exceeds its nominal value (see Fig. 8(d)) resulting from the zero sequence voltage reaching $60 \mathrm{~V}$ as shown in Fig. 8(g). The DC-link voltages become uncontrollable as shown in Fig. 8(f), thus resulting in distorted currents injected into the grid as seen in Fig. 8(c)).

(a)

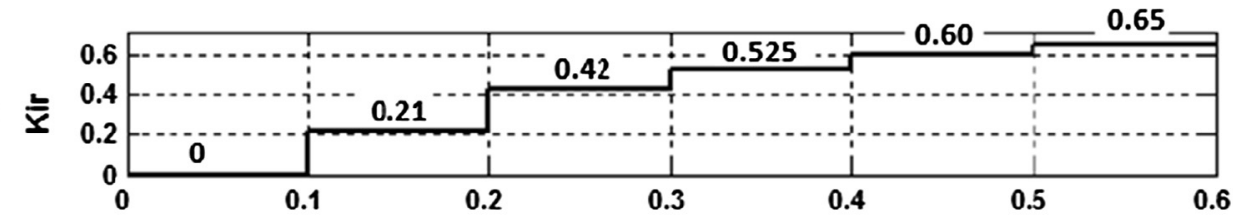

(b)

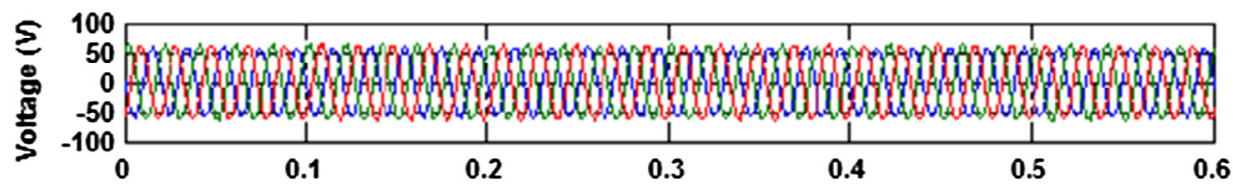

(c)

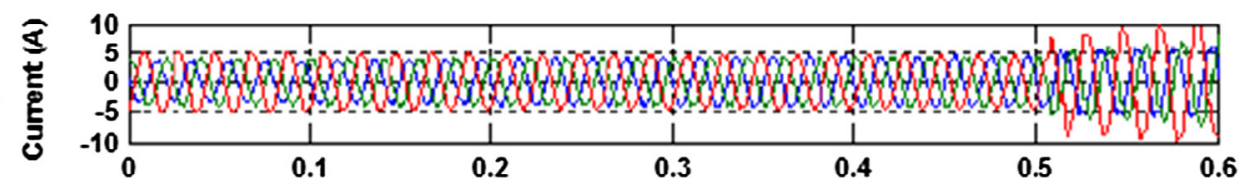

(d)

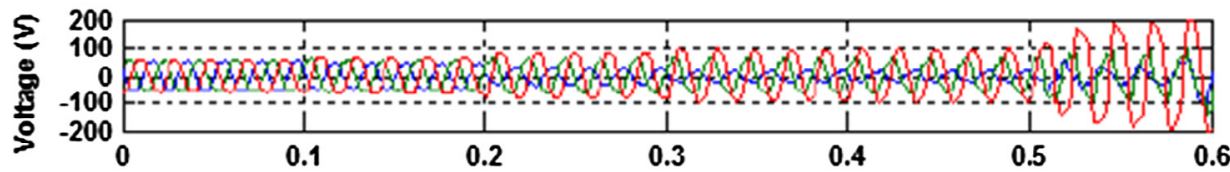

(e)

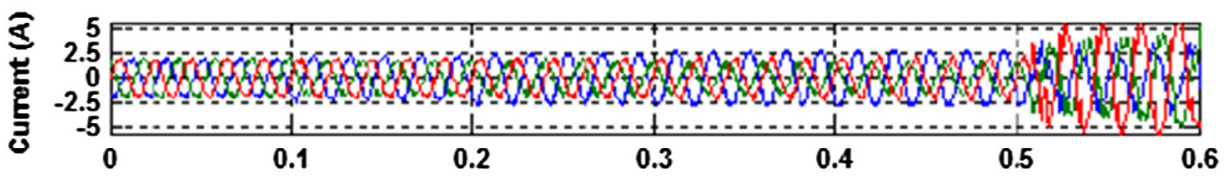

(f)

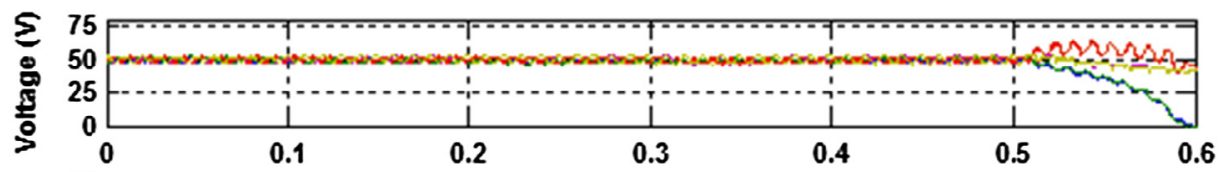

(g)

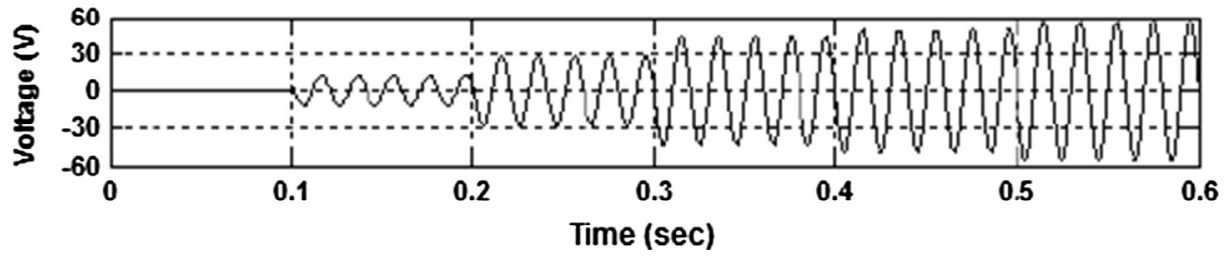

Fig. 8. Operating behaviour of SSBC under unbalance Load compensation. 
(a)

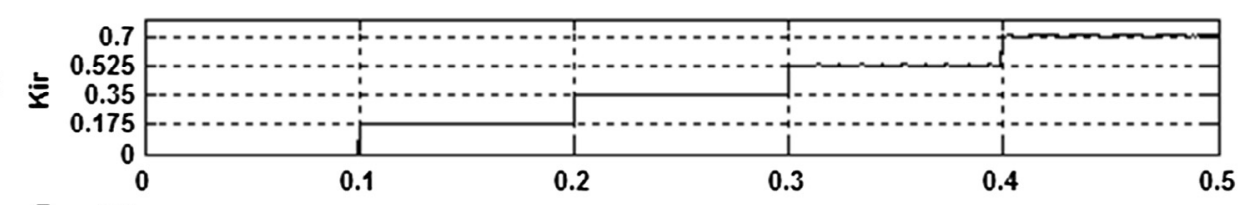

(b)

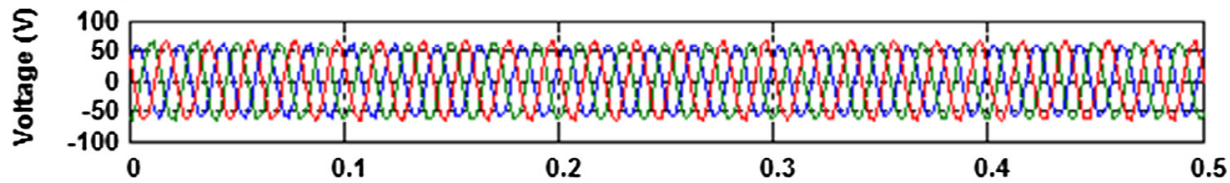

(c)

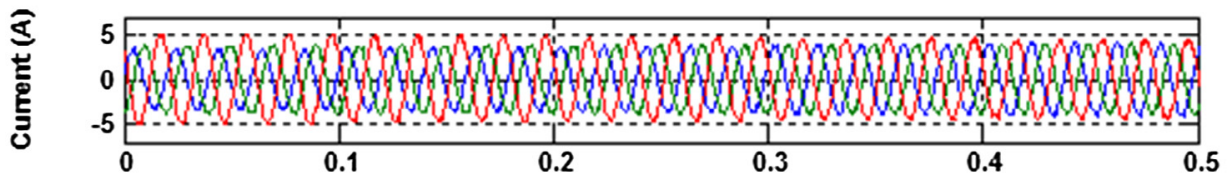

(d)

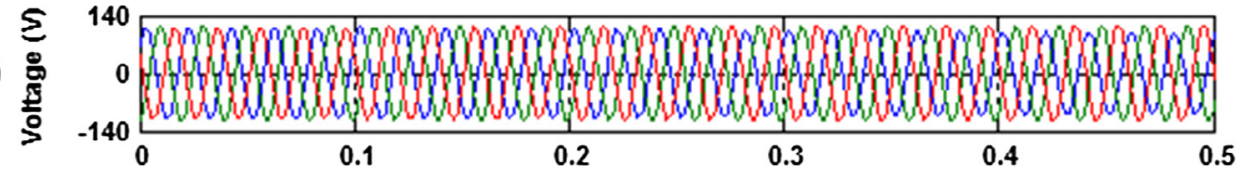

(e)

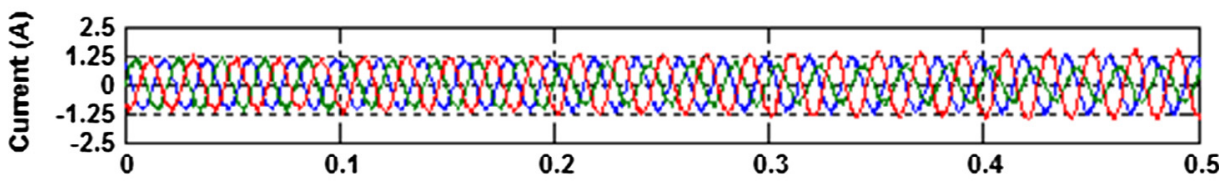

(f)

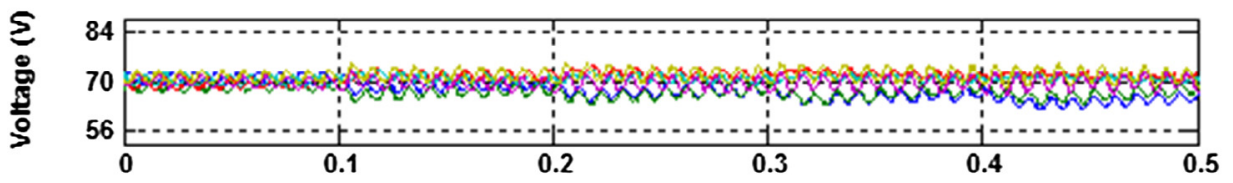

(g)

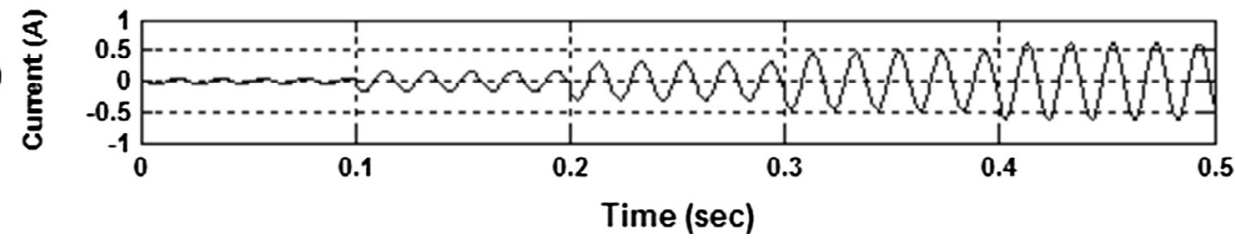

Fig. 9. Operating behaviour of SDBC under unbalance Load compensation.

For the SDBC STATCOM, the unbalance load is completely compensated as observed in Fig. 9. This results in the PCC current adequately balance (see Fig. 9(c)) also, the sub-module capacitor voltages are maintained at their rated values as shown in Fig. 9(f).

The modulation technique applied in controlling the MMCC STATCOM is the multilevel phase-shifted PWM (PS-PWM) scheme. This has been tested for this converter topology of 2 FCC submodules (effective $4 \mathrm{H}$-bridge sub-modules) per phase as presented in one of authors' previous publications [11]. Though the carrier frequency per module is $750 \mathrm{~Hz}$, the PS-PWM results in the harmonics in the MMCC phase voltage waveform being eight times of the carrier frequency and its sidebands, hence the most significant harmonic frequency is $750 \times 8=6000 \mathrm{~Hz}$ and those of its sidebands. Two plots showing the converter voltage waveform and its harmonic spectra with THD of $10.39 \%$ are presented in Fig. 10. The converter phase voltage spectra diagram shows clearly the harmonic frequencies at the specified frequency values.

To highlight the effectiveness of the STATCOM controller in compensating the positive sequence reactive current and negative sequence current at PCC, the power quality performance is shown through spectrum plot of the supply end current when using SDBC STATCOM. Fig. 11 shows that at the full compensation the current THD is a low $4.13 \%$. This gives a clear indication of good power quality performance, since the voltage at PCC is assumed wellbalanced and harmonic free. The SSBC case is not displayed because its capability is limited, thus resulting in injected distorted current when its sub-module capacitor voltages are unstable.

\section{Conclusion}

This paper investigated the capabilities of MMCC-based STATCOMs for load unbalance compensation, and covered both star (SSBC) and delta (SDBC)-connected STATCOMs. This study has shown the following:

1. For effective compensation of unbalanced load current, the starconnected MMCC-STATCOM requires injection of zero sequence voltage $\boldsymbol{v}_{\boldsymbol{o}}$, and the delta-connected requires zero sequence current $\boldsymbol{i}_{\boldsymbol{o}}$.

2. New equations were derived for $\boldsymbol{v}_{\boldsymbol{o}}$ as a function of the degree of load imbalance $\boldsymbol{K}_{\boldsymbol{i r}}=\boldsymbol{I}_{\boldsymbol{n}} / \boldsymbol{I}_{\boldsymbol{p}}$ for the SSBC converter, and for $\boldsymbol{i}_{\boldsymbol{o}}$ as a function of $\boldsymbol{K}_{i r}$ for the SDBC.

3. This study concluded that the SSBC converter has limited capability for unbalanced load compensation compared to the SDBC. This is because $\boldsymbol{v}_{\boldsymbol{o}}$ rises with the degree of load unbalance as measured by $\boldsymbol{K}_{\boldsymbol{i r}}$, and may results in the converter phase voltage rising above its rated level and unbalanced converter phase reference voltages. For the SDBC converter, the $\boldsymbol{i}_{\boldsymbol{o}}$ expression shows that an increase in $\boldsymbol{K}_{i r}$ results in a small increase in the phase cluster current. Even with $\boldsymbol{K}_{\boldsymbol{i r}}$ reaching $100 \%, \boldsymbol{i}_{\boldsymbol{o}}$ does not exceed $35 \%$ of the nominal value. 


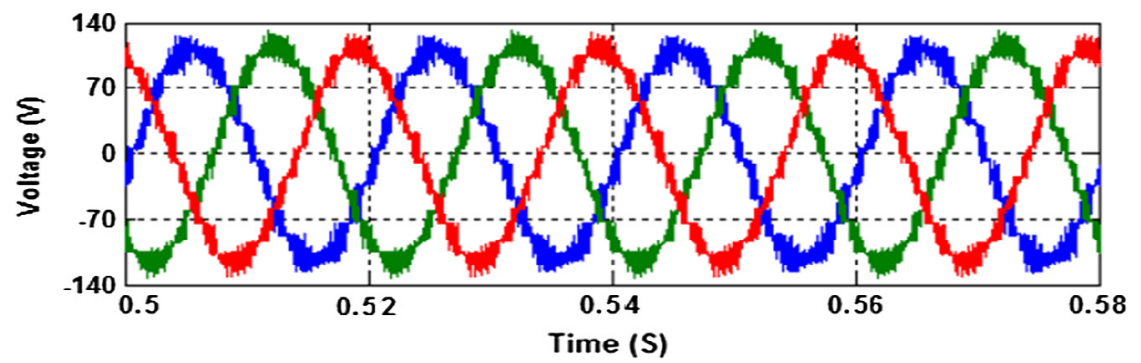

(a)

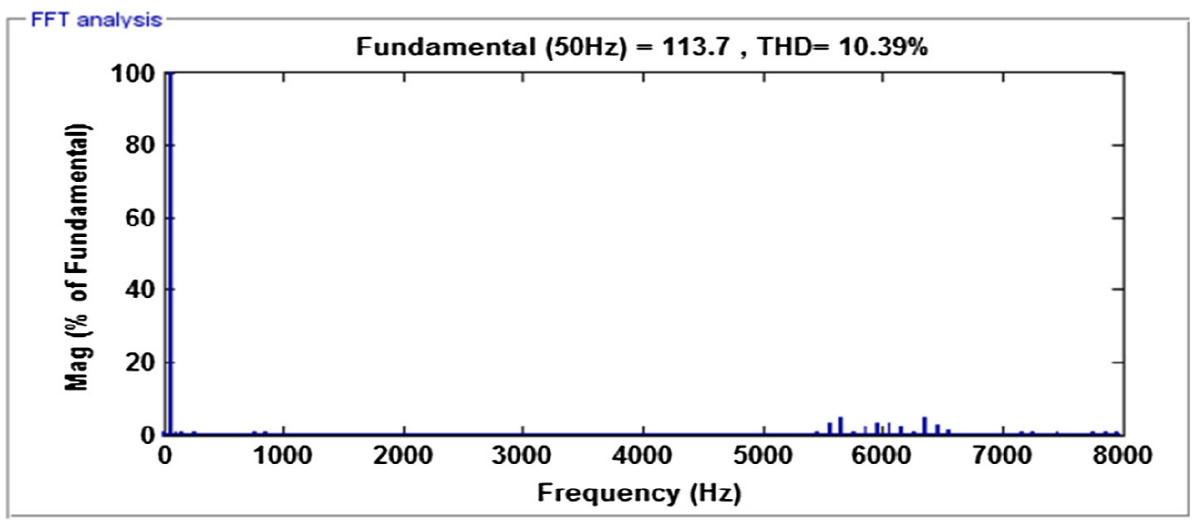

(b)

Fig. 10. (a) SDBC phase cluster voltage and (b) phase spectrum at full compensation.

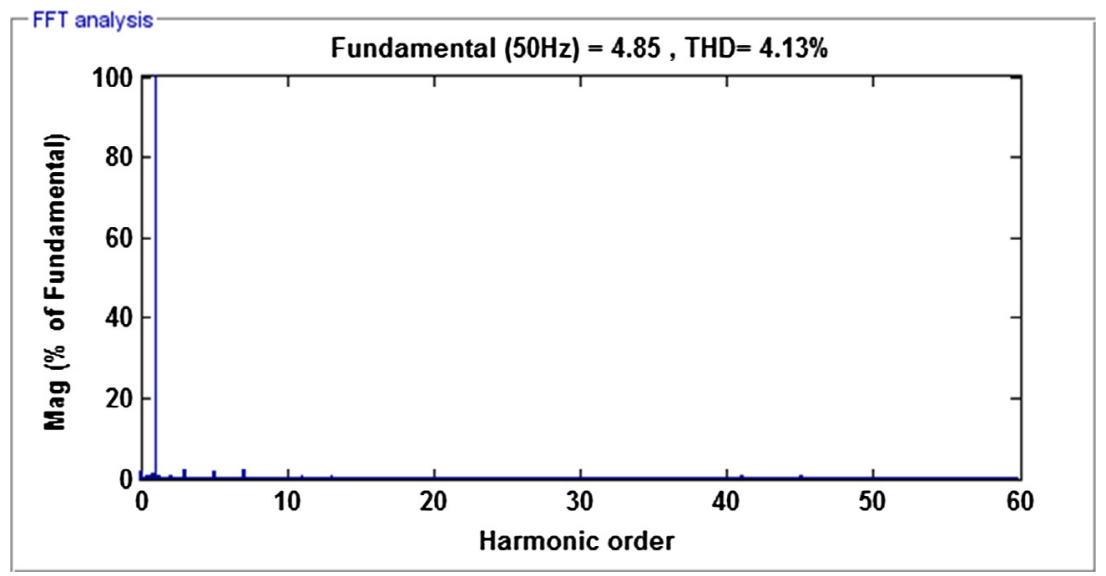

Fig. 11. Supply end phase current THD during full compensation of SDBC.

4. All the above results have been experimentally validated using an MMCC STATCOM with six modules. (Two per phase).

In summary, the SDBC offers superior capability in achieving unbalanced load compensation in comparison to the SSBC-based STATCOM. In future work it is planned to extend the SSBC's operational limit by injecting third order harmonics in its zero sequence voltage $\boldsymbol{v}_{\boldsymbol{o}}$.

\section{Appendix A}

A.1. Continuation of $\boldsymbol{v}_{\boldsymbol{o}}$ simplification

$\mathrm{N}$ and $\mathrm{D}$ are expressed in (A.1) and (A.2) as

$$
\begin{aligned}
N= & {\left[\left(P_{b}-X_{b 3}\right) X_{a 2}-\left(P_{a}-X_{a 3}\right) X_{b 2}\right] \sin \omega t+\left[\left(P_{a}-X_{a 3}\right) X_{b 1}\right.} \\
& \left.-\left(P_{b}-X_{b 3}\right) X_{a 1}\right] \cos \omega t
\end{aligned}
$$

$D=X_{a 2} X_{b 1}-X_{a 1} X_{b 2}$

Substitution of $\boldsymbol{X}_{\boldsymbol{a} 1}, \boldsymbol{X}_{\boldsymbol{a} 2}, \boldsymbol{X}_{\boldsymbol{b} 1}$ and $\boldsymbol{X}_{\boldsymbol{b} 2}$ into $\mathrm{N}$ and D yields

$N=\left(P_{a}-X_{a 3}\right)\left(I_{P} \cos \left(\omega t+\varphi_{i p}-\frac{2 \pi}{3}\right)-I_{n} \cos \left(\omega t+\varphi_{i n}+\frac{2 \pi}{3}\right)\right)$ $-\left(P_{b}-X_{b 3}\right)\left(I_{P} \cos \left(\omega t+\varphi_{i p}\right)-I_{n} \cos \left(\omega t+\varphi_{i n}\right)\right)$

$\mathrm{D}=\frac{\sqrt{3}}{2}\left(I_{p}^{2}-I_{n}^{2}\right)$ 
Substituting $\mathrm{N}$ and D terms in (23) with PCC voltage angle $\varphi_{V P}=0$ yields,

$$
\begin{aligned}
v_{o}= & \frac{2}{\sqrt{3} I_{p}^{2}\left(1-K_{i r}^{2}\right)}\left(I _ { p } \left(A_{a 1} \cos \left(\omega t+\varphi_{i p}-\frac{2 \pi}{3}\right)\right.\right. \\
& \left.-A_{b 1} \cos \left(\omega t+\varphi_{i p}\right)\right)+I_{n}\left(A_{a 1} \cos \left(\omega t+\varphi_{i n}+\frac{2 \pi}{3}\right)\right. \\
& \left.\left.-A_{b 1} \cos \left(\omega t+\varphi_{i n}\right)\right)\right)
\end{aligned}
$$

where $A_{a 1}=p_{a}-V_{P} I_{P} \cos \varphi_{i P}-V_{P} I_{n} \cos \varphi_{i n}$ and $A_{b 1}=p_{b}-V_{P} I_{P} \cos \varphi_{i P}+$ $\frac{1}{2} V_{P} I_{n} \cos \varphi_{\text {in }}-\frac{\sqrt{3}}{2} V_{P} I_{n} \sin \varphi_{\text {in }}$.

\section{Appendix B}

\section{B.1. Continuation of $\boldsymbol{i}_{\boldsymbol{o}}$ simplification}

The numerator $(\mathrm{N})$ and denominator (D) are simplified by substituting $\boldsymbol{X}_{\boldsymbol{a b} \mathbf{1}}, \boldsymbol{X}_{\boldsymbol{a b} \mathbf{2}}, \boldsymbol{X}_{\boldsymbol{b c} \mathbf{1}}$ and $\boldsymbol{X}_{\boldsymbol{b c} \boldsymbol{2}}$ into (B.1) and (B.2) respectively.

$$
\begin{aligned}
N= & {\left[\left(P_{b c}-X_{b c 3}\right) X_{a b 2}-\left(P_{a b}-X_{a b 3}\right) X_{b c 2}\right] \sin \omega t } \\
& +\left[\left(P_{a b}-X_{a b 3}\right) X_{b c 1}-\left(P_{b c}-X_{b c 3}\right) X_{a b 1}\right] \cos \omega t \\
D= & X_{a 2} X_{b 1}-X_{a 1} X_{b 2}
\end{aligned}
$$

Substitution of $\boldsymbol{X}_{\boldsymbol{a b} 1}, \boldsymbol{X}_{\boldsymbol{a b} 2}, \boldsymbol{X}_{\boldsymbol{b c 1}}$ and $\boldsymbol{X}_{\boldsymbol{b c} 2}$ into N and D yields

$$
N=\sqrt{3} V_{P}\left[\left(P_{a b}-X_{a b 3}\right) \cos \left(\omega t-\frac{\pi}{2}\right)-\left(P_{b c}-X_{b c 3}\right) \cos \left(\omega t+\frac{\pi}{6}\right)\right]
$$

$\mathrm{D}=\frac{3 \sqrt{3}}{2} V_{p}^{2}$

Combining $\mathrm{N}$ and D new terms in (31) with PCC voltage angle $\varphi_{V P}=0$ yields,

$$
\begin{aligned}
i_{0}= & \frac{2}{3} I_{P}\left[\left(\frac{P_{a b}}{V_{P} I_{P}}-\cos \varphi_{i p}-\frac{1}{2} K_{i r} \cos \varphi_{i n}-\frac{\sqrt{3}}{2} K_{i r} \sin \varphi_{i n}\right) \cos \left(\omega t-\frac{\pi}{2}\right)\right. \\
& \left.-\left(\frac{P_{b c}}{V_{P} I_{P}}-\cos \varphi_{i p}+K_{i r} \cos \varphi_{i n}\right) \cos \left(\omega t+\frac{\pi}{6}\right)\right]
\end{aligned}
$$

\section{References}

[1] Hingorani NG, Gyugyi L. Understanding FACTS: concepts and technology of flexible AC transmission systems. IEEE Press, John Wiley \& Sons; 2000.

[2] Sood VK. HVDC and FACTS controllers: applications of static converters in power system. Springer; 2004. edition.

[3] Zhang XP, Rehtanz C, Pal B. Flexible AC transmission systems: modeling and control. Berlin Heidelberg: Springer-Verlag; 2012.

[4] Abd-Elazim SM, Ali ES. Optimal location of STATCOM in multimachine power system for increasing loadability by Cuckoo search algorithm. Int J Electrical Power Energy Syst (IJEPES Elsevier) 2016;80 C:240-51.

[5] Abd-Elazim SM, Ali ES. Imperialist competitive algorithm for optimal STATCOM design in a multimachine power system. Int J Electrical Power Energy Syst (IJEPES Elsevier) 2016;76C:136-46.

[6] Abd Elazim SM, Ali ES. Optimal SSSC design for damping power systems oscillations via Gravitational Search Algorithm. Elsevier Electrical Power Energy Syst 2016;82:161-8.
[7] Govindaraj, V. Elango MK. Modular multilevel cascade converter based statcom for reactive power compensation. In: Circuits, power and computing technologies (ICCPCT), 2013 International Conference on; 2013.

[8] Yang X, Li J, Fan W, Wang X, Zhang T. Research on modular multilevel converter based STATCOM. In: Industrial electronics and applications (ICIEA), 2011 6th IEEE Conference on. IEEE; 2011.

[9] Song Wenchao, Huang Alex Q. Fault-tolerant design and control strategy for cascaded H-bridge multilevel converter-based STATCOM. IEEE Trans Ind Electron 2010;57(8)

[10] Hagiwara M, Maeda R, Akagi H. Application of a modular multilevel cascade converter (MMCC-SDBC) to a STATCOM. IEEE Trans Ind App 2011;131:1433-41.

[11] Nwobu C, Efika IB, Oghorada OJK, Zhang L. A modular multilevel flying capacitor converter-based STATCOM for reactive power control in distribution systems. In: Power electronics and applications (EPE'15 ECCE-Europe), 2015 17th European conference on. IEEE; 2015.

[12] Efika I, Nwobu C, Zhang L. Reactive power compensation by modular multilevel flying capacitor converter-based STATCOM using PS-PWM; 2014.

[13] Lee S-Y, Wu C-J. Reactive power compensation and load balancing for unbalanced three-phase four-wire system by a combined system of an SVC and a series active filter. IEE Proc - Electric Power Appl 2000;147(6).

[14] Blazic B, Papic I. Improved D-StatCom control for operation with unbalanced currents and voltages. IEEE Trans Power Delivery 2006;21(1):225-33.

[15] Ping-Heng W, Hsin-Chih C, Yi-Ting C, Po-Tia C. Delta-connected cascaded Hbridge converter application in unbalanced load compensation. In: Energy conversion congress and exposition (ECCE), 2015 IEEE; 2015.

[16] Betz RE, Summers T, Furney T. Symmetry compensation using a H-bridge multilevel STATCOM with zero sequence injection. In: Industry applications conference, 2006. 41st IAS Annual Meeting. Conference record of the 2006 IEEE; 2006.

[17] Fujun Ma, An Luo, Qiaopo Xiong, Zhixing He, Qian Xu. Derivation of zerosequence circulating current and the compensation of deltaconnected static var generators for unbalanced load. IET Power Electron 2016;9(3):576-88.

[18] Shi Y, Lui B, Shi Y, Duan S. Individual phase current control based on optimal zero-sequence current separation for a star-connected cascade STATCOM under unbalanced conditions. IEEE Trans Power Electron 2016;31 (3):2099-110.

[19] Maosong Z, Qunjing W. Implementation of a cascade D-STATCOM under unbalanced conditions. In: Electronics and application conference and exposition (PEAC), 2014 International; 2014.

[20] Nieves M, Maza JM, Mauricio JM, Teodorescu R, Bongiorno M. Enhanced control strategy for MMC-based STATCOM for unbalanced load compensation. In: Power electronics and applications (EPE'14-ECCE Europe), 2014 16th European conference on; 2014.

[21] Sixing D, Jinjun L. A study on DC voltage control for chopper-cell-based modular multilevel converters in D-STATCOM application. IEEE Trans Power Delivery 2013;28(4):2030-8.

[22] Summers TJ, Betz RE, Mirzaeva G. Phase leg voltage balancing of a cascaded Hbridge converter based STATCOM using zero sequence injection. In: Power electronics and applications, 2009. EPE '09. 13th European conference on; 2009.

[23] Qiang S, Wenhua L. Control of a cascade STATCOM with star configuration under unbalanced conditions. EEE Trans Power Electron 2009;24(1):45-58.

[24] Oghorada O, Nwobu C, Zhang L. Control of a single-star flying capacitor converter modular multi-level cascaded converter (SSFCC-MMCC) STATCOM for unbalanced load compensation; 2016.

[25] Yifan Y, Konstantinou G, Hredzak B, Agelidis VG. On extending the energy balancing limit of multilevel cascaded $\mathrm{H}$-bridge converters for large-scale photovoltaic farms. In: Power engineering conference (AUPEC), 2013 Australasian Universities; 2013.

[26] Yifan Y, Konstantinou G, Hredzak B, Agelidis VG. Power balance optimization of cascaded H-bridge multilevel converters for large-scale photovoltaic integration. IEEE Trans Power Electron 2016;31(2):1108-20.

[27] Bailu X, Lijun H, Jun M, Riley C, Tolbert LM. Modular cascaded H-bridge multilevel PV inverter with distributed MPPT for grid-connected applications. IEEE Trans Ind Appl 2015;51(2):1722-31.

[28] Yifan Y, Konstantinou G, Hredzak B, Agelidis VG. Power balance of cascaded Hbridge multilevel converters for large-scale photovoltaic integration. IEEE Trans Power Electron 2016;31(1):292-303.

[29] Sochor P, Akagi H. Theoretical comparison in energy-balancing capability between star- and delta-configured modular multilevel cascade inverters for utility-scale photovoltaic systems. IEEE Trans Power Electron 2016;31 (3):1980-92. 